\title{
Extending prevention of mother-to-child transmission through postpartum family planning in Lesotho
}

Charlotte E. Warren

Population Council

Semakaleng Phafoli

Bosielo Majara

Thato Tsukuluet

Follow this and additional works at: https://knowledgecommons.popcouncil.org/departments_sbsr-rh

Part of the Demography, Population, and Ecology Commons, International Public Health Commons, Maternal and Child Health Commons, and the Women's Health Commons How does access to this work benefit you? Let us know!

\section{Recommended Citation}

Warren, Charlotte E., Semakaleng Phafoli, Bosielo Majara, and Thato Tsukuluet. 2008. "Extending prevention of mother-to-child transmission through postpartum family planning in Lesotho," FRONTIERS Final Report. Washington, DC: Population Council. 


\title{
Extending Prevention of Mother-to-Child Transmission through Postpartum Family Planning in Lesotho
}

\author{
Frontiers in Reproductive Health
}

Charlotte Warren

Semakaleng Phafoli

\section{Family Health Department, Ministry of Health and Social Welfare \\ Bosielo Majara \\ Thato Tšukulu}

September 2008

This study is made possible by the generous support of the American people through the Regional HIV AIDS Program (for Southern Africa), United States Agency for International Development (USAID) under the terms of Cooperative Agreement Number HRN-A-00-98-00012-00, In-house Project 8812 53107. The contents are the responsibility of the FRONTIERS Program and do not necessarily reflect the views of USAID or the United States Government.
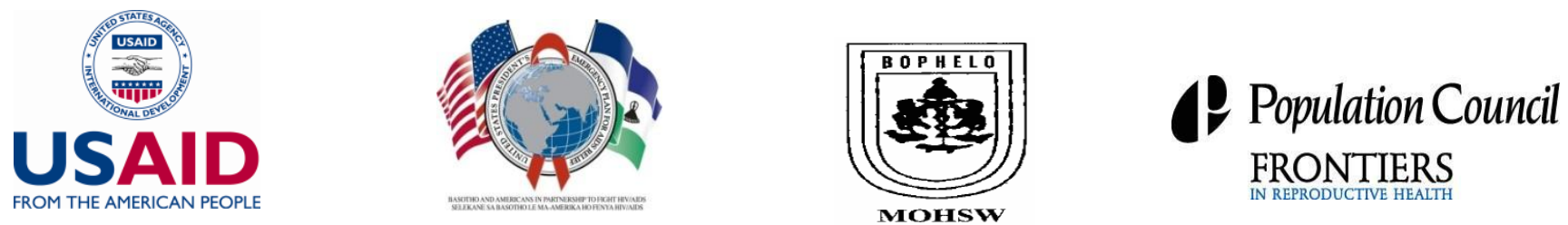


\section{ACKNOWLEDGEMENTS}

The Ministry of Health and Social Welfare of the Kingdom of Lesotho and the Population Council would like to thank those who made this operations research study possible. Work of this nature would not have been possible without the invaluable hard work and commitment of the health providers and social scientists that formed field teams to collect data. Special thanks go to all the pregnant women and postpartum women in Butha Buthe who participated in the study; without them the research would not have been possible.

We would also like to recognize the financial and technical support from Regional HIV and AIDS Program (RHAP) of United States Agency for International Development (USAID) through the Frontiers in Reproductive Health Program of the Population Council. 


\section{SUMMARY}

Recognizing the need to improve the care and follow up of mothers and infants in the postpartum period, the Lesotho Ministry of Health and Social Welfare (MOHSW), with technical support from the Frontiers in Reproductive Health Program (FRONTIERS) of Population Council and funding from PEPFAR/RHAP/USAID, carried out an operations research project to strengthen the existing postpartum care services. In Lesotho, only 28 percent of new mothers receive a checkup after delivery (LDHS 2004). The prevention of future unintended pregnancies as a strategy and fundamental component of PMTCT programs has not received much attention to date, and is the focus of this project. This study has a specific focus on strengthening linkages with existing PMTCT follow up services and family planning services during the postpartum period by changing the number, timing and content of postpartum consultations that a woman and her newborn should receive. The objectives of the study were: 1) to develop and introduce a strengthened postpartum care package with three consultations within 48 hours, one week and six weeks; and 2) to document the feasibility and quality of care of the strengthened postpartum care package, and its acceptability to providers and postpartum women.

Researchers used a pre- and post-test design to assess the effectiveness of the new postpartum package of care in the district hospital and four public health centers in Butha Buthe District in the north of Lesotho. To assess quality of care within the facilities, data were collected through interviews with health care providers, structured observations of client-provider interactions and a facility checklist for assessing availability of equipment and supplies to provide PNC. Women were also interviewed on the postnatal ward before and after the intervention. Focus group discussions with both providers and clients took place following the intervention to assess the acceptability of the new services. Data collection took place in October 2006 and July 2007.

A postpartum package of care was developed by FRONTIERS in conjunction with the MOHSW and stakeholders from national institutions. Results from the baseline data contributed to developing training materials, job aids and an information leaflet. A postpartum register was also introduced and piloted in the intervention sites. Essential items of equipment were distributed to the health facilities. The training package was pre-tested in another district (Leribe District) with similar characteristics to Butha Buthe district. Three supervision visits were made to the five intervention facilities between March and May 2006. Twenty-four providers were trained over three days from 16 health facilities in the districts. All 24 providers made an action plan to introduce the PNC services into their places of work and update their colleagues.

The key findings were as follows:

- Facilities were prepared or needed minimal adjustments to provide the PNC services. In each area assessed (staff training, services offered, equipment, drugs, FP commodities and vaccines), results indicate that the selected sites had the capacity to provide postpartum care.

- Provider knowledge improved: Significant increases were noted in several aspects of postpartum care, but some gaps in knowledge of on maternal and newborn health care remain.

- Provider practice improved, demonstrating a commitment to quality of care for mothers and babies in both $\mathrm{MCH}$ and the maternity unit. A majority of women and their newborns 
were given a comprehensive check up within 48 hours, one week and 6 weeks after delivery. Immunization coverage remained high and counseling on infant feeding improved significantly.

- Increase in women testing for HIV: significantly more postpartum clients had tested for HIV after introducing the intervention, with the majority of tests taking place during antenatal care (ANC) consultations. More women were referred to the ART clinic post intervention.

- Increase in proportion of providers who would recommend LAM and condoms to postpartum women at 48 hours, two weeks and 6 weeks. "LAM is cheap and accessible while the condom prevents further re-infection".

- Majority of women said they intended to use FP between 6 weeks and 6 months. Despite this encouraging trend, women's understanding of when they might be able to conceive following childbirth did not change and remained low after the intervention.

Providers and new mothers in Butha Buthe district were enthusiastic about the timing of the new postpartum package of services. The MOHSW should now make efforts to sustain this initiative and roll out the package to the rest of the country. The results of this study have come at an opportune time and will feed into new initiatives currently underway. Feedback from national stakeholders following the dissemination meeting in March 2008 included overwhelming support for scaling up the number, timing and content of postpartum consultations that a woman and her newborn should receive.

Policy issues that need to be addressed include the following:

- Strengthen policies related to the continuum of care for maternal, newborn and infant health and linked to HIV/PMTCT/ strategies.

- Facilitate the necessary system processes through organizational changes, such as allocation of staff, availability of physical space and equipment/ supplies and efficient client flow, as they are critical for the adequate provision of the new focused postpartum services.

- All training materials and job aids developed by MOHSW and the Population Council may be formally adopted for scaling up PNC services.

- Strengthen linkages between the facility and community levels for institutionalizing the new PNC package.

- Develop a family planning training strategy to update providers' skills for providing long-term methods.

- In institutions managed by the Christian Health Association of Lesotho, which are primarily Roman Catholic, encourage LAM and other fertility-based awareness methods.

- Suggest roles for community health workers (CHWs) on MNH/FP activities including the provision of counseling during home visits and community mobilization on preventive aspects of care, identification of danger signs, ANC and PNC periods for the mother and baby. 


\section{Table of Contents}

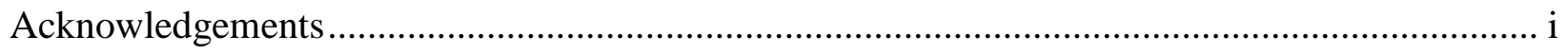

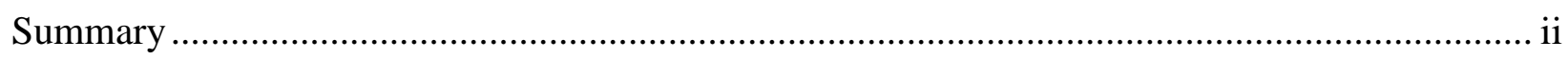

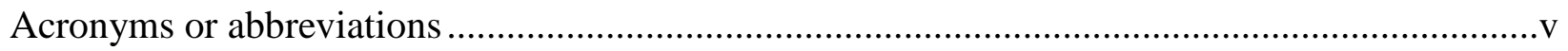

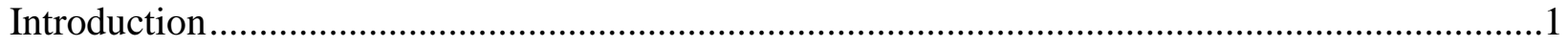

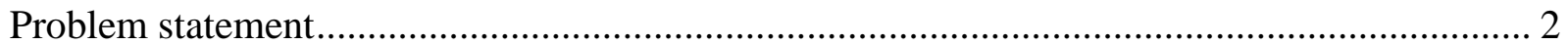

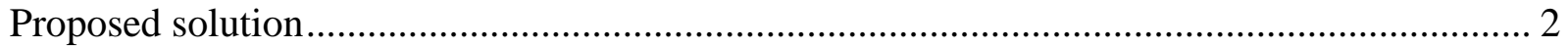

Revised and Focused Package of Postpartum Care .....................................................................

Development of the postpartum orientation package .................................................. 4

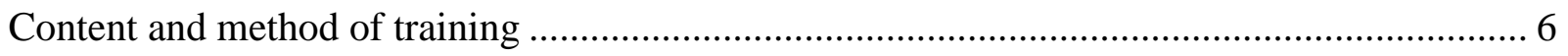

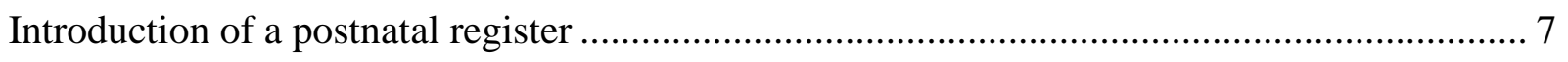

Ensuring availability of minimum levels of equipment and supplies ................................ 7

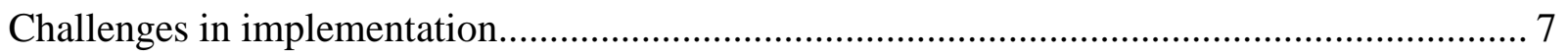

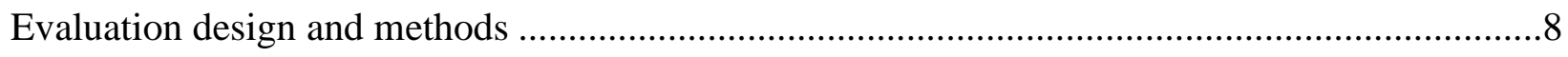

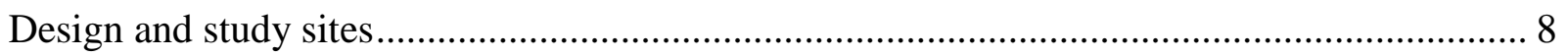

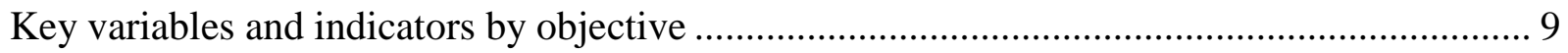

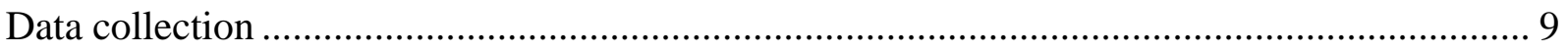

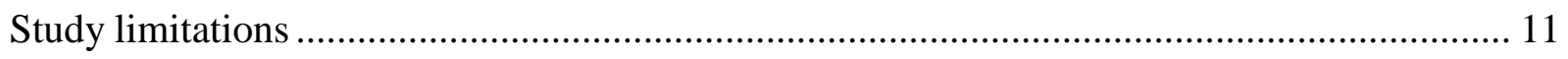

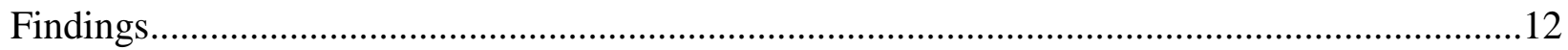

Characteristics of women receiving postpartum services ............................................ 12

Facility preparedness to offer the new postpartum package ............................................. 12

Provider knowledge in maternal and newborn care ........................................................ 14

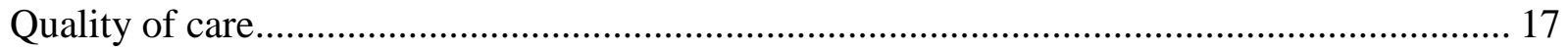

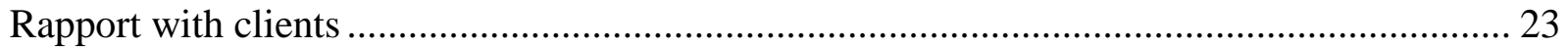

Acceptability of new postpartum services .................................................................... 23

Women's knowledge and experiences during labor and postpartum period ........................ 25

Follow up counseling and support in the postpartum period ............................................. 27

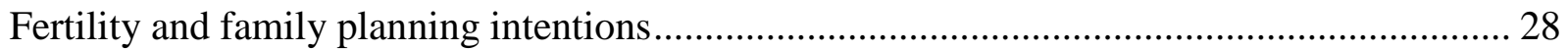

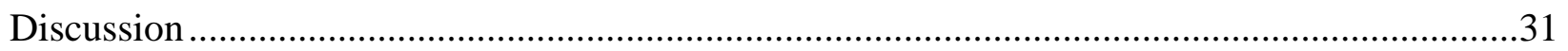

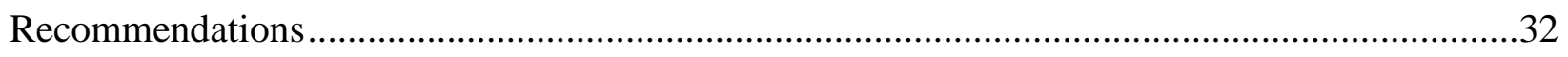

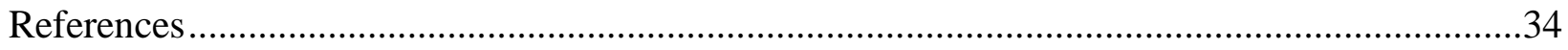




\section{ACRONYMS OR ABBREVIATIONS}

AIDS Acquired Immune Deficiency Syndrome

ANC Antenatal Care

ARV Antiretroviral

ART Antiretroviral Therapy

BCG Baccile Calmette Guerin

CHAL Christian Health Association of Lesotho

CHW Community Health Worker

CPR Contraceptive Prevalence Rate

COC Combined Oral Contraceptive

CS Caesarean Section

CTX Cotrimoxazole

DHS Demographic Health Survey

DPT Diphtheria, Pertussis, Tetanus

EGPAF Elisabeth Glaser Pediatric AIDS Foundation

FGD Focus Group Discussion

FP Family Planning

HIV Human Immunodeficiency Virus

HTSP Healthy Timing and Spacing of Pregnancies

IEC Information, Education and Communication

IUD Intra Uterine Device

LAM Lactational Amenorrhea Method

LDHS Lesotho Demographic Health Survey

$\mathrm{MCH} \quad$ Maternal and Child Health

MNH Maternal and Newborn Health

MOHSW Ministry of Health and Social Welfare

OR Operations Research

PPH Postpartum Hemorrhage

PMTCT Prevention of Mother-to-Child Transmission

PNW Postnatal Ward

POP Progestin Only Pill

RH Reproductive Health 


$\begin{array}{ll}\text { RHAP } & \text { Regional HIV /AIDS Program } \\ \text { STI } & \text { Sexually Transmitted Infections } \\ \text { TB } & \text { Tuberculosis } \\ \text { TBA } & \text { Traditional Birth Attendant } \\ \text { USAID } & \text { United States Agency for International Development } \\ \text { VCT } & \text { Voluntary Counseling and Testing } \\ \text { WHO } & \text { World Health Organization }\end{array}$




\section{INTRODUCTION}

Lesotho continues to have one of the highest rates of HIV infection in the world, with 24 percent of adults aged 15 to 49 years being infected and prevalence among women aged 25 to 39 years even higher, at 40 percent (LDHS 2005). Progress has been made in scaling up national programs for prevention of mother to child transmission (PMTCT) of HIV. Integrated antenatal care (ANC) and PMTCT services provide an entry point for pregnant women to be tested for HIV as well as accessing anti-retroviral (ARV) prophylaxis from 28 weeks gestation, during early labor and for the newborn after birth and into the postpartum period.

One of the main challenges for PMTCT programs is the follow-up of mothers and infants after delivery and very little attention has been given to the early postpartum period (from birth to six weeks). This is the most vulnerable time for the health of the mother and infant. In Lesotho, the majority of women (90 percent) attend antenatal care at least once and 70 percent attend four or more times (LDHS 2005). Skilled health personnel attend 55 percent of births, with almost all of these occurring in a facility. Relatives or friends attend 30 percent of births and traditional birth attendants (TBAs) attend 13 percent of births. The maternal mortality ratio is 762 per 100,000 live births (LDHS 2004); the neonatal mortality rate is 40 per 1,000 live births, with 84 percent of the deaths occurring within the first week of life, and the stillbirth rate is 26 per 1,000 total births. Seventy-two percent of women in Lesotho do not receive a postpartum check up. Of the 28 percent who do receive postpartum care, only 23 percent receive a checkup within two days of the birth. Some women attend for the first time at six weeks when they bring their newborn baby for immunization and/or for family planning; however, this is not necessarily recorded as a postpartum visit.

Over 60 percent of maternal deaths occur in the first 48 hours after childbirth (WHO 2005) and there is increasing evidence that maternal deaths related to HIV are rising (Gray and McIntyre 2005, McIntyre 2005, Lewis 2004). For many women in southern Africa, the postpartum period is a time of increased susceptibility to HIV and STIs. Three-quarters of newborn deaths occur in the first week and of those, two-thirds occur in the first 24 hours (WHO 2005). Although HIV infection in the mother will influence the outcome for the baby, practically all neonatal deaths in the first month of life are due to non-HIV causes (e.g. asphyxia, sepsis and prematurity), highlighting the need to address the quality of basic maternal and newborn care generally and not just among HIV-positive mothers. It has been estimated that if 90 percent of babies and mothers received routine PNC, 10 to 27 percent of newborn deaths could be averted (Warren et al 2006).

For those pregnant women who deliver in a health facility, the immediate postpartum period when the woman is still at the facility provides a timely and strategic opportunity to offer a range of services that could maintain a continuity of care that started during the ANC visits and continued during labor and delivery.

One particularly neglected area during the postpartum period is family planning. Lesotho does not have an explicit family planning policy and service providers have few guidelines to follow and 
may create their own rules and restrictions (Tuoane et al 2004) ${ }^{1}$. The contraceptive prevalence rate (CPR) nationally is 37 percent and the total fertility rate (TFR) is 3.5. The most common methods of family planning currently used by married women in Lesotho include injectables (15 percent), pills (11 percent), and the IUD (2 percent). Although women using these methods may be protected against unintended pregnancy, they are not protected against STIs, including HIV. Condom use within regular partnerships is five percent (LDHS 2005).

\section{Problem statement}

The scale of the HIV epidemic among pregnant women has led to the rapid roll out of PMTCT programs in Lesotho. Voluntary Counseling and Testing (VCT) services and ARVs are now available at selected facilities. There remain concerns, however, about the degree to which these services have been integrated into existing antenatal and postpartum services. Primary prevention of HIV and reduction of unintended pregnancies amongst HIV positive women are two key components of WHO's comprehensive PMTCT strategy (WHO 2004), but both have been given little attention (Rutenberg and Baek 2004). At the time of the 2004 DHS in Lesotho, the national HIV policy made no reference to family planning at all (Strachan et al 2004).

Postpartum care is weak in Lesotho. Recording of service statistics is poor and no postpartum register exists. The existing guidelines expect women to attend a clinic for the first time six weeks after delivery. Women may bring their newborn baby for immunization. Others may also attend for family planning. However, women do not receive a comprehensive checkup nor is it necessarily recorded as a postpartum visit. The family planning needs of women during the postpartum period, and particularly those who are HIV positive, are often not addressed during antenatal care or immediately after delivery, leaving many women at risk of unintended or wrongly timed future pregnancies. Providing continuity of care between ANC, PMTCT, delivery, postpartum care and during the extended postpartum period can ensure that women's fertility intentions in the context of their HIV status are fully and effectively met. The prevention of future unintended pregnancies as a strategy and fundamental component of a PMTCT program is the focus of this project.

\section{Proposed solution}

The solution developed to address this problem was to strengthen the existing postpartum program with a specific focus on follow-up of women after receiving PMTCT and providing family planning information and services by changing the number, timing and content of postpartum consultations that a woman and her newborn should receive. This project

The Christian Health Association of Lesotho (CHAL) manages about 40 percent of all health facilities in Lesotho. Although salaries are paid by the Government, member churches influence the facilities' operations. About one half of the sites are operated by the Roman Catholic Church and do not provide modern contraceptive methods, although individual staff may do so (Tuoane 2004). 
complemented the on-going "Partners for Family-Centered HIV Programs"2 that was already supporting activities to strengthen PMTCT. In September 2006, there was no systematic follow up of HIV-positive postpartum women.

The Lesotho National Reproductive Health Guidelines currently recommend one postpartum visit at six weeks after delivery. The revised postpartum package tested in this study recommended that women and their infants receive three consultations during the postpartum period. The first should be within 48 hours of delivery and within the maternity unit or postnatal ward if she delivered at a health center or hospital. The second consultation should be within one week after delivery, preferably at a facility in the maternal and child health $(\mathrm{MCH})$ clinic. The third consultation should be at six weeks, again preferably at an $\mathrm{MCH}$ clinic. The content of each consultation would be specific for the timing of the visit, i.e. it would be 'focused' postpartum care.

The overall goal of this project was to enable all new mothers and their partners to achieve their fertility desires and to live healthily through improving postpartum care and support. The two immediate objectives were to:

1. Develop and introduce a strengthened postpartum care package with three consultations at 24 hours, one week and six weeks.

2. Document the feasibility and quality of care of the strengthened postpartum care package, and its acceptability to providers and postpartum women.

\section{REVISED AND FOCUSED PACKAGE OF POSTPARTUM CARE}

The design of the intervention was based on discussions with the MOHSW and other national stakeholders, and information gathered through site visits to the hospital and health centers and the baseline assessment. In summary, the intervention comprised:

- Development of training materials on postpartum care and postpartum family planning.

- Technical job aids guiding health providers on actions to take during postpartum consultations.

- A leaflet for parents that provides information on care of the mother and baby during the postpartum period.

- Introduction of a postnatal register to be piloted in the selected sites.

- Orientation of providers in postpartum care.

- Procurement of essential equipment and supplies.

2 The Partnership for Family-Centered HIV Programs is a consortium of organizations funded through USAID's Regional HIV/AIDS Program that collaborates with the Government of Lesotho to reduce the impact of HIV/AIDS, with specific emphasis on reducing HIV-related morbidity and mortality among children, women and their families. The development of an integrated family-centered approach to HIV care included incorporating a package of PMTCT services into routine antenatal and postnatal consultations, establishing supportive services for HIV pregnant women and their families as well as providing HIV care and treatment to all HIV infected pregnant women, their HIV exposed infants, infected children, partners and family members. 


\section{Development of the postpartum orientation package}

Training materials on reproductive health in Lesotho were originally developed in the late 1980s and early 1990s, and had very little focus on maternal and newborn health or on family planning. Pre-service training provides basic information, but family planning is not covered in much detail and there are limited opportunities to practice skills learnt; minimal in-service reproductive health training is available. There are no up-to-date FP guidelines, very few health providers are skilled in family planning, and no family planning course available in Lesotho. Recently there has been an upsurge in training for health workers, but all with a focus on HIV and PMTCT.

To support strengthening the postpartum services package, the Population Council's Frontiers in Reproductive Health program (FRONTIERS) developed a postpartum orientation package and technical job aids grounded in evidence and adapted from WHO and other relevant training materials from the Africa region. To develop the new postpartum package, existing national guidelines and standards were reviewed. Consultations with the MOHSW and partners and a joint review of the baseline findings in November 2006 resulted in an agreed upon outline of a minimum package of postpartum care. The new package for providers was subsequently developed and linkages with HIV/AIDS - PMTCT services made where relevant. This was reviewed and amended at a meeting of stakeholders in January 2007 and subsequently finalized in early 2008 after the endline assessment.

The postpartum orientation package is a collection of training materials and activities that aims to highlight key, useful and practical points for providers. It incorporates materials such as the national guidelines or strategies and critical information that providers need to remember in dayto-day practice, compiled into job aids. The new postpartum package focuses on the integration of essential care for all postpartum mothers and newborns as part of a continuum of care extending from initial contact during antenatal services. Figure 1 outlines a summary of the essential services to be provided for each specific visit during the continuum of care from the first antenatal visit to six week postpartum. Postpartum women with HIV and their infants, and women with low birth weight infants, may require additional assessments.

Technical job aids were developed to assist health providers on the postnatal ward and at the $\mathrm{MCH}$ clinics. These included checklists of activities to carry out during the consultations for the mother and infant within 24 hours and at the one week consultation. In addition, family planning information on the most appropriate methods following childbirth and key information on the lactational amenorrhea method (LAM) was adapted from WHO and other sources. Examples of these materials are given in the annex.

To assist postpartum women and their families to retain the information given to them on the postnatal ward, a "parent" leaflet was also developed. The leaflet provides information on care of the mother and newborn, advice on breastfeeding and family planning, danger signs to look out for in both mother and baby, and the need for follow up care, especially for women living with HIV. Once the Department of Health Education had given its approval, the parent leaflet was translated into Sesotho, printed and distributed on the postnatal ward (see annex). 
Figure 1: $\quad$ Timing and content of the PPC-FP package of care

\begin{tabular}{|c|c|c|}
\hline Assessment & Services for mother & Services for baby \\
\hline $\begin{array}{l}\text { Assessment 1: } \\
\text { Pre-discharge } \\
\text { (or within } 48 \\
\text { hours if } \\
\text { delivered at } \\
\text { home) }\end{array}$ & $\begin{array}{l}\text { Focused physical exam } \\
\text { Counseling on early breastfeeding (EBF) } \\
\text { and LAM } \\
\text { Healthy Timing and Spacing of } \\
\text { Pregnancies FP } \\
\text { Maternal danger signs and management } \\
\text { of complications } \\
\text { HIV \& anemia tests as indicated } \\
\text { Refer to Comprehensive Care Centers } \\
\text { (CCC) for HIV follow up as indicated } \\
\text { Appointment for next visit }\end{array}$ & $\begin{array}{l}\text { Early exclusive breastfeeding } \\
\text { Essential newborn care } \\
\text { Newborn physical exam } \\
\text { Newborn danger signs and } \\
\text { management of complications } \\
\text { Nevirapine as indicated } \\
\text { Infant feeding counseling } \\
\text { Immunizations BCG and Polio } \\
\text { Appointment for next visit }\end{array}$ \\
\hline $\begin{array}{l}\text { Assessment 2: } \\
\text { One week at } \\
\mathrm{MCH} \text { clinic }\end{array}$ & $\begin{array}{l}\text { Physical check } \\
\text { Maternal danger signs and management } \\
\text { of complications } \\
\text { EBF counseling } \\
\text { Healthy Timing and Spacing of } \\
\text { Pregnancy (HTSP messages) } \\
\text { Return to sexual activity } \\
\text { Return to fertility } \\
\text { LAM and FP counseling and services } \\
\text { Refer to ART clinic if required } \\
\text { Appointment for next visit }\end{array}$ & $\begin{array}{l}\text { Essential baby care } \\
\text { Baby danger signs and } \\
\text { management of complications } \\
\text { Immunization } \\
\text { Exclusive breast feeding } \\
\text { Infant feeding review } \\
\text { Physical examination } \\
\text { ARV if required } \\
\text { Appointment for next visit }\end{array}$ \\
\hline $\begin{array}{l}\text { Assessment 3: } \\
\text { Six weeks at } \\
\text { MCH clinic }\end{array}$ & $\begin{array}{l}\text { Focused physical examination } \\
\text { Maternal danger signs and management } \\
\text { of complications } \\
\text { LAM users- supportive counseling } \\
\text { including transition } \\
\text { HTSP messages } \\
\text { FP counseling and services (refer } \\
\text { women for methods not available at } \\
\text { Health Centers) } \\
\text { Dual method use } \\
\text { Return to fertility and sexual activity } \\
\text { CTX prophylaxis if required } \\
\text { Refer to ART clinic if required for follow } \\
\text { up CD4 count etc } \\
\text { Return visit }\end{array}$ & $\begin{array}{l}\text { Essential baby care } \\
\text { Danger signs and } \\
\text { management of illnesses } \\
\text { Immunization } \\
\text { Physical exam } \\
\text { EBF } \\
\text { Cotrimoxazole at } 6 \text { weeks } \\
\text { if required } \\
\text { Refer to ART clinic if required } \\
\text { Refer for HIV testing } \\
\text { Appointment for next visit }\end{array}$ \\
\hline
\end{tabular}

The final version of the PPC-FP orientation package is composed of two main parts plus annex:

\section{Section I}

- Overview of care/objectives of training

- Major causes of maternal and neonatal mortality

- Overview of Focused ANC and linkages to focused PPC

- Description of postpartum care and four focused assessments

- Maternal complications in postpartum period (hemorrhage, sepsis and eclampsia)

- Integrating HIV into focused PNC

- $\mathrm{TB}$ in postpartum period

- Infant feeding

- Care of the sick newborn. 


\section{Section II}

- Postpartum family planning

- LAM

- Long-term FP methods

- Voluntary surgical contraception

- Hormonal contraception

- Summary.

Annexes: Supportive job aids for trainees

- Essential actions for postpartum assessments (48 hours, one week and 6 weeks)

- FP in the postpartum period: postpartum FP methods compatible with breastfeeding and the appropriate timing to introduce contraceptive methods

- Parent leaflet

- References

\section{Content and method of training}

The training focused on four issues:

1. Implementation of appropriate timings and quality care during postpartum visits for the mother and the baby, and their integration with PMTCT services.

2. Promotion of the importance of having postpartum consultations at 48 hours and one week during antenatal clinics and during labor and delivery, and their integration with PMTCT services.

3. Facilitation of organizational changes to promote effective provision of care during postpartum consultations;

4. Supervision to improve and maintain quality of services rendered.

The orientation included a description of the new package, overviews of regular antenatal care, (emphasizing the gaps encountered in the baseline evaluation), content of the packages of care at each consultation, with a focus on family planning. Other elements included site preparation and then necessary organizational changes in supervision, monitoring and evaluation. All aspects of the new package were linked to PMTCT - HIV and AIDS services where possible. The content was delivered as short lectures, discussions and group work. Pre and post tests were conducted and the biggest improvements were seen in knowledge of infant feeding and immediate postpartum and newborn care. At the end of the two and a half day orientation, all health providers drew up an action plan for implementing the strengthened postpartum care package within their own facilities.

The training orientation package was piloted in January 2007 in Leribe District with eight service providers drawn from the hospital and health centers. Based on this experience, changes were made to the curriculum prior to the training in Butha Buthe district. For the intervention itself, 
training took place over two and a half days in February 2007. The 16 participants included nurse clinicians, registered nurses or nursing assistants from the hospital and all four health centers; no doctors were available for training ${ }^{3}$.

Supervision visits took place in March and April 2007 by the National Program Office for Family Planning (FP), the District Public Health Nurse and FRONTIERS staff. Each facility was visited and the process of implementing the new package discussed, including a review of the action plan developed during training. The postnatal register was piloted in all five sites, and the health providers using it gave their input on its 'usability'; alternatives were suggested to ensure that all services were captured.

\section{Introduction of a postnatal register}

Prior to introducing the intervention, health providers were unable to record all the services rendered to postpartum women and their infants; some information was recorded in the immunization/under fives register and some in the family planning register. However these only recorded the immunizations or family planning method given, i.e. they served as a 'commodity' register. FRONTIERS supported introduction of a postnatal register that had been piloted and validated in Kenya. The register was piloted in Butha Buthe District and amended to the Lesotho context through input from health providers working in the clinics and senior health managers. This register is now under review at the national level with a view to utilizing it as a standard register across the country.

\section{Ensuring availability of minimum levels of equipment and supplies}

Basic equipment needed for the provision of this package of care that was found lacking in the hospital and health centers during the baseline assessment was provided during the intervention period by FRONTIERS. Such equipment included: blood pressure machines, stethoscopes, specula and battery operated lamps. Family planning methods were made available by the MOHSW; shortages of some contraceptive methods during the intervention were beyond the control of the project.

\section{Challenges in implementation}

Some challenges were identified by health providers during a half day follow-up review meeting in April 2007. These included:

\section{Client health-seeking behaviors:}

- Many women make their first ANC visit late in pregnancy and therefore do not receive sufficient information about PMTCT and preparation for birth and the postpartum period.

- Some women do not want to be tested for HIV.

- Not all pregnant women return for follow-up care after finding out they are HIV positive.

- Some mothers are afraid to disclose their HIV status to their spouse.

- Women often have difficulty accessing health facilities due to the geography and climate, especially during winter, leading to a high proportion of home deliveries.

- Many women do not come for the one week postpartum check.

3 Two Cuban obstetricians had been based in Butha Buthe Hospital but they left in early 2007 and were not replaced immediately. 


\section{Health system challenges:}

- Lack of essential equipment, unavailability/inconsistent supply of FP commodities, HIV test strips.

- Poor infrastructure, crowded rooms and lack of adequate light.

- Insufficient staffing.

- Insufficient skills, specifically in long-term FP method provision.

- Frequent rotation of staff to different facilities and units and for night duty.

During the supervision visit in April, one key problem that emerged was the fact that in some facilities the providers do not reside on-site, even though accommodation exists. Most staff travel from Butha Buthe every morning and the clinic is only open 08.00 - 16.30 hours, Monday to Friday. This means there is no health care at night or over the weekend for the population living within the clinic catchment area. Moreover, although the recommendation is that all women should give birth in the hospital, a sizable proportion of women are unable to reach the hospital in time. Staffing health centers in rural areas continues to be a problem generally for the MOHSW. Emigration and attrition due to HIV/AIDS continues to undermine the workforce in many small southern African countries.

\section{EVALUATION DESIGN AND METHODS}

\section{Design and study sites}

To assess outcomes of the intervention, a baseline assessment to measure provider and client knowledge and behaviors around postpartum care was conducted during September - October 2006 and an endline assessment in June - July 2007, five months after introduction of the intervention in February 2007. Prior to conducting the baseline assessment, the research tools were pre-tested in Leribe Government Hospital and appropriate changes incorporated.

A pre - posttest only design was used to assess the feasibility, acceptability and quality of care of the newly introduced postpartum package of care in one hospital and four health centers (HCs) in Butha Buthe District in Lesotho. Butha Buthe District is situated in the north of Lesotho, approximately two hours north east of the capital Maseru, bordering the province of Free State Province in South Africa. The district hospital and four HCs were purposively selected as study sites by the Family Health Division of MOHSW because Butha Buthe Hospital had started comprehensive PMTCT services (supported by MOHSW and the USAID-funded Partnership for Family Centered HIV programs) in 2006 and all the HCs provide some related services. The sites are representative of other hospitals and health centers across the country. St Peter's and St Paul's HCs are supported by CHAL and are administered by the Roman Catholic Church. Khabo and Makhumoane HCs are public health facilities. St Paul's HC is situated on the outskirts of Butha Buthe town whereas the remaining three HCs are off the tarmac roads; Makhumoane HC is high up in the hills and a 1.5 hour car journey from the town. 


\section{Key variables and indicators by objective}

The following variables and indicators were measured to be able to achieve the study objectives:

\section{Operational Variables}

Objective 1: To develop and introduce a strengthened postpartum care program with three consultations at 24 hours, one week and six weeks

- Proportion of women who state the preferred timing for FP messages in ANC, PNC or both

- Proportion of PP women who can cite at least: (i) two components of basic preventive newborn care, and (ii) two danger signs in the baby that requires care seeking

- Proportion of PP women who can cite at least: (i) two components of basic preventive maternal care, and (ii) two danger signs in the mother that requires care seeking.

- Proportion of infants receiving immunizations increased

- Proportion of women who intend to start FP method by 6 weeks

Objective 2: To document the feasibility and quality of care of the strengthened postpartum care package, and its acceptability to providers and clients.

\section{Feasibility of implementation}

- Facility readiness to offer the comprehensive focused postpartum package (i.e., infrastructure, equipment, supplies, medicines registers, forms, IEC materials, support staff available).

- Provider knowledge and skills improved

Acceptability to providers

- Providers indicating approval and satisfaction with offering comprehensive PPC package

- Proportion of providers expressing confidence in their ability to provide PNC

- Number of clients given dates to return for PN care

Acceptability to clients

- Proportion of PP women who can recall the essential information on postpartum care that they received during ANC

- Proportion of women who would recommend the postpartum services to others

\section{Data collection}

Similar data collection tools were used for both the baseline and the endline assessments.

1. In-depth interviews with $\mathrm{MCH} / \mathrm{midwifery}$ staff: Short structured interviews with health providers were used to assess their knowledge and skills for postpartum and newborn care, as well as their attitudes toward satisfaction with the package. All health providers working in the $\mathrm{MCH}$ clinics and on the maternity ward at the hospital were approached for interview. Butha Buthe Hospital has around 25 staff in total, and the HCs have four or five staff per center. All of the health providers were female and either nurse midwives, nurse clinicians or nursing assistants. Twelve health providers were interviewed at baseline and 21 at endline. 
The number of years worked at the facilities ranged from one year to 27 years. At endline, around half of the providers were nursing assistants (two years training) and half were registered nurse midwives or nurse clinicians (three years training). The same health providers were not necessarily interviewed at both baseline and endline. Before the intervention, some of the health providers in the hospital refused to be interviewed, citing the fact that they were too busy. However after the intervention no-one refused; $36 \%$ of all hospital staff participated as did $80 \%$ of providers working in $\mathrm{MCH}$ or maternity (those working nights were not interviewed).

2. Interviews with women on the postnatal ward: These were held to determine the acceptability of the pre-discharge services provided on the ward, both before and after introduction of the revised care package. The client questionnaire was also translated into Sesotho. Data collectors were newly qualified or retired midwives who attended three-day training in research methods including role playing to internalize the questionnaire items and the ethics of research process. Women in the postnatal ward at Butha Buthe hospital were interviewed within 48 hours of giving birth. Researchers requested interviews with all women on the postnatal ward (i.e. all consecutive clients) over a four week period. The interviews recorded all information that postpartum women received from staff during ANC consultations, on the labor ward and on the postnatal ward about care of themselves and the baby, including infant feeding counseling, and care of the mother and baby including recognition of danger signs. All women were asked about their fertility intentions and if they received any advice on family planning or were given condoms to take home.

3. Direct observation of client-provider interactions: Qualified nurse midwives were trained to observe and record aspects of postpartum consultations to measure provider competence and their ability to follow service provider guidelines for care using a standardized checklist. To reach a meaningful measure of quality of care with a relatively small sample size, 12 client-provider interactions were expected to be observed in each of the following categories of consultation:

a. For the pre-discharge consultation (within 48 hours) after introduction of the package;

b. For the one-week consultation after introduction of the package in the $\mathrm{MCH}$ clinics;

c. For the six-week consultation, before and after introduction of the package in the $\mathrm{MCH}$ clinics.

4. Facility Checklist: An inventory was made of available resources necessary for providing the postpartum package of care, e.g. infrastructure, equipment, commodities, test kits, ARV drugs and other medications and stationery required to provide the services, and staffing.

5. Focus group discussions: FGDs were carried out after the intervention with providers and postpartum women to seek a deeper understanding and elicit experiences and perceptions of the new postpartum consultation at one week; and the integration of services and measures to improve PNC. Twelve FGDs were held: four at Butha Buthe Hospital: two for health care providers (registered nurses and nursing assistants) and two for postpartum clients (postpartum women who attended either the one week or six week postpartum consultation). In addition two FGDs (one for health care providers and one for postpartum women) were held at each of the four health centers. The majority $(60 \%)$ of providers $(n=18)$ who attended the FGDs were nursing assistants. Each FGD lasted approximately one and a half hours. After 
each FGD, the tapes were transcribed and translated into English. Subsequently results were coded and then grouped into concepts and themes and a report written. The qualitative researcher travelled to the district of Butha-Buthe during July 2007 for data collection. Data collection and analysis were scheduled to take five weeks, but took nine weeks because of political instability and bad climatic conditions.

Informed consent was obtained from all respondents who were assured that participation would involve minimal risk and that the information would be confidential prior to each interview. Supervisors checked all completed questionnaires for data quality and accuracy.

Quantitative data were entered using Epi Info and later converted to SPSS for analysis. Table 1 describes the sample sizes achieved for each of the data collection tools. Generally, Pearson's Chi square test was used to determine the significance of any differences between the pre and post intervention results. A p-value of less than 0.5 was used as the threshold for significance. In this report, a single asterisk $(*)$ indicates that the results are statistically significant below the 0.05 level and a double asterisk (**) indicates that the results are statistically significant below the 0.01 level.

Table 1: Summary of data collection tools and sample sizes

\begin{tabular}{l|cccc}
\hline Data collection tool: & \multicolumn{2}{c}{ Pre-intervention } & \multicolumn{2}{c}{ Post-intervnetion } \\
\cline { 2 - 5 } & $\frac{\text { Hosp }}{2}$ & $\frac{\text { HC }}{10}$ & $\frac{\text { Hosp }}{8}$ & $\frac{\underline{H C}}{13}$ \\
Provider interview & 46 & & 64 & \\
Client interview within 48 hours on postnatal ward & & & 34 & \\
Observation within 48 hours on postnatal ward & & & 36 & 15 \\
Observation at one week in hospital and PNC clinics & & 19 & 31 & 19 \\
Observation at 6 weeks in hospital and ANC clinics & 19 & 4 & & \\
Facility assessment tool & 1 & & 2 & 4 \\
Provider focus group discussion & & & 2 & 4 \\
Client focus group discussion & & & & \\
\hline
\end{tabular}

\section{Study limitations}

Although the health facilities are typical of those found across Lesotho, this study had some limitations that make the interpretation of the data, particularly about change over time among staff, challenging. The study was facility-based and all women interviewed delivered in a facility, which represents about 55 percent of women giving birth in Lesotho. These women tend to be better educated and have higher income and so may not be representative of all postpartum women in the country. The client-provider observations of services at 48 hours were only recorded at the district hopsital for the post-intervention group. Observations of services for the one-week and six-week visits included clients that did not deliver at either the hospital or one of the study health centers and so they may have different needs or characteristics compared to women who delivered at the hospital. Because of staff shortages there were few staff available for interview and very few were interviewed both pre and post intervention. In addition rotation and deployment issues affect the length of time any provider may stay in one place or unit. 


\section{FINDINGS}

\section{Characteristics of women receiving postpartum services}

The characteristics of the postpartum women interviewed during the pre-intervention and post interviention assessments are described in Table 2. In summary, both groups of women interviewed were similar in most aspects. The only significant differences were that more women at endline than at baseline were above 35 years (the mean age at baseline was 23.5 years and 26.3 years at endline) and had completed high school. These differences in age group may potentially influence women's fertility and FP intentions.

Table 2: Characteristics of postpartum women interviewed

\section{Characteristics:}

Age 15-19 years

Age 20-24 years

Age 25-29 years

Age 30 - 34 years

Age 35 years and over*

Primary or lower school

Secondary school

Completed high school or above*

Parity (average pregnancies per mother)

Gravida (average full term deliveries per mother)

Child ever died

HIV positive

HIV negative

Tested but does not know results

Attended antenatal clinic

Attended two to three times

Attended four or more times

\begin{tabular}{|c|c|}
\hline $\begin{array}{c}\text { Pre- } \\
\text { intervention }\end{array}$ & $\begin{array}{c}\text { Post- } \\
\text { intervention }\end{array}$ \\
\hline$(\mathrm{N}=46)$ & $(\mathrm{N}=64)$ \\
\hline $24 \%$ & $15 \%$ \\
\hline $43 \%$ & $37 \%$ \\
\hline $15 \%$ & $20 \%$ \\
\hline $17 \%$ & $15 \%$ \\
\hline $0 \%$ & $12 \%$ \\
\hline $46 \%$ & $36 \%$ \\
\hline $43 \%$ & $36 \%$ \\
\hline $11 \%$ & $28 \%$ \\
\hline 1.93 & 2.27 \\
\hline 1.87 & 2.27 \\
\hline $9 \%$ & $14 \%$ \\
\hline $16 \%$ & $16 \%$ \\
\hline $73 \%$ & $75 \%$ \\
\hline $11 \%$ & $9 \%$ \\
\hline $98 \%$ & $95 \%$ \\
\hline $22 \%$ & $40 \%$ \\
\hline $71 \%$ & $51 \%$ \\
\hline
\end{tabular}

\section{Facility preparedness to offer the new postpartum package}

Prior to introducing the intervention, the "preparedness" of facilities to implement the postpartum package was assessed in terms of availability and functioning of the basic infrastructure, equipment and supplies necessary for offering quality services. An index of clinic preparedness was constructed using six indicators; all items are considered to be necessary for providing postpartum care:

1. Availability of services (Score range: 0-13) included weighing the client, taking blood pressure, health education sessions, counseling for HIV, birth preparedness and family planning, blood tests (anemia, syphilis and HIV), urine testing, vaccinations (TT), PMTCT and STI treatment. 
2. Availability of essential equipment (Score range: $0-10)$ incorporated essential items such as BP machine, stethoscope, foetoscope, scales (adult and infant), tape measure, thermometer, speculum, examination couch and spotlights.

3. Availability of essential drugs (Score range: 0-11) included the expected range of micronutrient supplements, antibiotics, (such as cotrimoxazole, gentamicin and amoxicillin in tablet, injection and syrup forms) and ARVs tablets and syrups (nevirapine, AZT, ZDV, Combivir).

4. Availability of essential vaccines (Score range: 0- 6) BCG, Polio, DPT, HBV, measles and tetanus toxoid.

5. Availability of essential family planning methods (Score range: 0 - 9) Injectables, COC, POP, IUD, male and female condoms, implants, female and male sterilization.

6. Availability of in-service staff trainings within past year (Score range 0-23) ranged from updates in different aspects of PMTCT, HIV counseling and support to comprehensive antenatal care, screening and STIs, management of labor, newborn care (low birth weight, sick newborn), infant feeding and postpartum care.

Data were drawn from the facility inventories, mean scores computed for each indicator, and then aggregated across all indicators to give the total composite score for clinic preparedness.

At the baseline, all facilities had the capacity to provide strengthened postpartum care (see Table 3), with Butha Buthe Hospital scoring the highest. Khabo Health Centre was least likely to have essential equipment or had drugs that were missing. At the time of the baseline, the new ARV prophylaxis regime of AZT, ZDV and Combivir had not yet started and so none of the facilities had these drugs.

St Paul's and St Peter's HCs are run by CHAL and do not provide any FP methods, but they do advise women where services are available. The most commonly available family planning commodities were combined oral contraceptive (COC), progestin only pill (POP), injectables and male condoms. The IUD was available in two public health facilities but only one (BB hospital) had the insertion kit. Implants are not yet available in any public health facilities in Lesotho.

Table 3: Summary of health facilities' preparedness at baseline

\begin{tabular}{l|ccc}
\hline & $\begin{array}{c}\text { BB Hospital } \\
\text { \& Health Centers }\end{array}$ & $\begin{array}{c}\text { BB Hospital } \\
\text { Only }\end{array}$ & $\begin{array}{c}\text { Health Centers } \\
\text { Only }\end{array}$ \\
\hline Availability at baseline: & $\begin{array}{c}\text { Average } \\
\text { score }\end{array}$ & $\begin{array}{c}\text { Average } \\
\text { score }\end{array}$ & $\begin{array}{c}\text { Average } \\
\text { score }\end{array}$ \\
& $(\mathrm{N}=5)$ & $(\mathrm{N}=1)$ & $(\mathrm{N}=4)$ \\
Services offered (0-13) & 11 & 11 & 11 \\
Equipment available (0-10) & 7 & 10 & 7 \\
Drugs (0-16) & 12 & 11 & 12 \\
Vaccinations (0 - 6) & 6 & 6 & 6 \\
Family planning methods (0-9) & 4 & 6 & 4 \\
In-service staff training in past year ( 0-23) & 18 & 22 & 16 \\
Total score (0-77) & $58(75 \%)$ & $66(86 \%)$ & $50(65 \%)$ \\
\hline
\end{tabular}


Registers, guidelines and protocols do exist in Lesotho for ANC, family planning, STIs, child welfare clinic, immunizations and sick infants (IMCI), but there are no standardized postpartum care registers. None of the health facilities, however, had all of the registers available. BB hospital was more likely to have the family planning register, guidelines and cards, although both public health centers also had registers for FP. St Peter's Health Centre was the only facility to have protocols for the sick newborn and postpartum care. Standard guidelines on HIV were seen in BB Hospital and St Peter's HC. Khabo HC was least likely to have relevant registers or guidelines. Postpartum registers were introduced at time of training. Lack of some of the FP methods was beyond the control of the project due to delays in contraceptive commodities arriving in country. Essential equipment was procured and distributed to sites during the intervention period. The draft orientation package and job aids were made available to all health facilities in the district.

\section{Provider knowledge in maternal and newborn care}

After the intervention, a larger proportion of providers (15 out of 21) reported having been oriented in family planning guidelines than at baseline (3 out of 12) and oriented in postpartum care (16 out of 21 vs. 0 out of 12). Provider knowledge was measured using a scale aggregating scores from indicators of the main causes of maternal and neonatal morbidity and mortality. The scores were generated from the provider questionnaire and an average score computed for each component. As most of the respondents at baseline and endline were not the same as there was high staff turnover, it should be noted that these data are difficult to interpret in terms of assessing the effect of the intervention.

Complications in the postpartum period: The orientation package touched only briefly on complications in the postpartum period. The two most common complications in the postpartum period for the mother are postpartum hemorrhage (PPH) and sepsis. There were no improvements in providers' knowledge on signs of PPH (from a mean score of 3.17 to 1.95 out of 4), which included un-contracted uterus ( $83 \%$ vs. $76 \%$ ), signs of shock (67\% vs. 29\%), amount of external bleeding (75\% vs. $24 \%$ ) and retained placenta (92\% vs. $67 \%)$. Knowledge of essential actions for managing PPH (massage the fundus, empty the woman's bladder, give IV oxytocin, and start IV fluids) also showed no significant changes, from a mean score of 3.17 to 2.71 out of four.

Table 4 indicates that knowledge on all signs of puerperal sepsis also decreased (although none of them significantly), with the composite score decreasing from 3.58 to 1.95 out of a possible 5 . There were no significant changes in knowledge of management of sepsis after the evaluation from 1.92 out of 3 to 1.38 out of 3 . Clearly there is a need for further improvements in this area, including both pre-service and in-service training. 
Table 4: Proportion of providers able to state signs for detecting sepsis in the mother during the postpartum period

\begin{tabular}{l|cc}
\hline \multicolumn{1}{c|}{ Indicator } & $\begin{array}{c}\text { Pre- } \\
\text { intervention } \\
(\boldsymbol{n = 1 1 )}\end{array}$ & $\begin{array}{c}\text { Post- } \\
\text { intervention } \\
(\boldsymbol{n = 2 1 )}\end{array}$ \\
\hline Signs of sepsis: & & \\
High pulse & $75 \%$ & $38 \%$ \\
High fever & $75 \%$ & $48 \%$ \\
Septic shock (un-recordable BP) & $75 \%$ & $48 \%$ \\
Tender abdomen & $58 \%$ & $55 \%$ \\
\hline
\end{tabular}

Provider's knowledge of signs of newborn infection was as follows: difficulty feeding (92\% vs. $81 \%)$, poor temperature control (67\% vs. $43 \%$ ) and breathing difficulties ( $75 \%$ vs. $43 \%$ ).

Table 5 describes the level of knowledge for managing newborn complications. Deployment and the technical capacity of nursing assistants to manage newborn complications, which usually occur on the labor ward, are the same as above.

Table 5: Provider knowledge of signs and actions to manage newborn complications

\begin{tabular}{l|cc}
\hline \multicolumn{1}{c|}{ Indicator } & $\begin{array}{c}\text { Pre- } \\
\text { intervention } \\
(\boldsymbol{n = 1 1 )}\end{array}$ & $\begin{array}{c}\text { Post- } \\
\text { intervention } \\
(\boldsymbol{n}=\mathbf{2 1})\end{array}$ \\
\hline & Mean & Mean \\
Signs of newborn infection $(0-3)^{*}$ & 2.33 & 1.67 \\
Action for newborn infection $(0-3)^{*}$ & 2.92 & 1.71 \\
Care of low birth weight baby $(0-5)^{* *}$ & 2.50 & 1.91 \\
Total performance on newborn complications $(\mathbf{0}-\mathbf{1 1}) *$ & $7.75(70 \%)$ & $5.57(51 \%)$ \\
\hline *p<0.05 **p<0.01
\end{tabular}

In addition to the few providers available, poor scores on maternal and newborn complications is most likely due to the redeployment and transfer of staff trained to other facilities. Most providers giving care at $\mathrm{MCH}$ clinics are nursing assistants who are not expected to manage obstetric complications, and PPH is most likely to occur in the labor/delivery ward or postnatal ward. The total score is only half of what is expected for a quality service and there is clearly a need for further improvements in this area.

Infant feeding: There were no significant changes in provider responses on knowledge of infant feeding, although fewer providers. However, when asked specifically about counseling women for PMTCT, all health providers at the endline said they would recommend exclusive breastfeeding for 6 months and 67 percent would advise postpartum women to wean abruptly at 6 months. 
PMTCT: The majority (90\%) of health providers recommended that all postpartum women should receive routine counseling and testing for HIV if their status is unknown. Health providers' knowledge that if the mother is sick, transmission of HIV to her infant is more likely improved after the intervention (67\% vs. 74\%). Provider knowledge of other factors that may increase transmission such as early mixed feeding, high maternal viral load, low CD4 count and advanced HIV infection or AIDS did not change significantly.

Family planning: During the interviews health providers were asked which family planning methods they would normally recommend to women within the first six weeks following childbirth. It should be noted that two of the health centers are supported by the Roman Catholic Church where staff can only advise on where to seek FP services.

After the intervention, significantly more providers said they would counsel breastfeeding women to use LAM from birth ( $8 \%$ vs. $62 \%$ ). More providers said they would continue to counsel women who were one week postpartum to use LAM ( $8 \%$ vs. $71 \%$ ); and providers would also counsel women to use LAM at 6 weeks (17\% vs. 43\%). When asked why they would recommend LAM and condoms, the most frequent replies from health providers included: "LAM is cheap and accessible, while the condom prevents further re-infection"; and "...because condoms can be used as a contraceptive and used to prevent STIs and HIV/AIDS”.

Several providers implied during the FGDs that while there is now more dialogue on LAM as a method of family planning, there are still many providers and women who do not wholly 'trust' LAM as a method to be used on its own. One informant felt that if a provider did not believe in LAM she is unlikely to recommend it to clients. However, the staff in CHAL institutions (where no modern method is available) were pleased to encourage LAM.

Long-acting FP methods: Providers were asked which FP methods they normally recommend to postpartum women. Most mentioned short-acting methods (pills, injectables and condoms). They were then asked why they did not normally recommend long-acting methods. While the majority of providers recognized that long-acting methods do not prevent infection or re-infection of STIs and HIV, their responses demonstrated limited knowledge and misperceptions surrounding longacting FP methods. IUDs are perceived as risky and likely to cause infection especially, among HIV-positive women. Some providers also said that because HIV-positive women have poor wound healing they would not recommend the implant as it involves an incision. However the overriding issue is that the providers do not have sufficient knowledge on the range of available methods nor the skills to insert either the IUD or the hormonal implants or to carry out female or male sterilization. While women could be counseled on the long-acting methods and referred for provision, many want to go home with a method and not have to wait. Women may be referred to the hospital, but travelling from the mountainous areas to the busy hospital is a deterrent for many women unless they have another reason to travel. The providers in the Catholic health institutions also have very limited knowledge of where the long-acting methods are available. Male sterilization is not culturally acceptable to Basotho men. 


\section{Quality of care}

Client-provider interactions were observed to assess the quality of care provided after the intervention on the postnatal ward at Butha Buthe Hospital at 48 hours and in the four MCH -FP clinics at one weeks and six weeks after the intervention. The 48 hour and two week consultations were not carried out routinely prior to the intervention and so none were observed; six week consultations were also observed before the intervention. The full range of maternal and newborn health services, including family planning, which are components of the new focused postpartum package were assessed through these structured observations of client-provider interactions and mean scores computed for each indicator and then aggregated across all indicators to give composite scores.

\section{Essential maternal care}

Asking about danger signs since childbirth: The following danger signs were noted: bleeding since birth, color/smell of vaginal discharge; condition of episiotomy site or perineal tears/condition of CS scar; fever; headache or blurred vision; swelling in face, hands or feet; signs of thrombophlebitis; tiredness or breathlessness; convulsions or fits. At the six weeks consultation, only four major signs are expected to be screened (bleeding, vaginal discharge condition of perineum/CS scar and fever).

In all consultations providers are expected to ask postpartum women if they have experienced any of these problems since birth, and should also counsel women on potential symptoms of complications. As Table 6 shows, for the majority of consultations within 48 hours of delivery, women were asked about any bleeding since birth, the color and smell of their lochia, although few asked about the condition of the perineum or signs of thrombosis. At 48 hours the mean composite score was 2.65 out of four.

\section{Table 6: Proportions (\%) of women asked about maternal danger signs during the three postpartum consultations after the intervention}

\begin{tabular}{l|ccc}
\hline \multirow{2}{*}{ Asking about danger signs: } & $\begin{array}{c}\mathbf{4 8} \text { hours } \\
(\boldsymbol{n}=\mathbf{3 4})\end{array}$ & $\begin{array}{c}\mathbf{1} \text { week } \\
(\boldsymbol{n}=\mathbf{5 1})\end{array}$ & $\begin{array}{c}\text { 6 weeks } \\
(\boldsymbol{n}=\mathbf{5 0})\end{array}$ \\
\cline { 2 - 4 } & $\%$ & $\%$ & $\%$ \\
Heavy bleeding since birth & 82 & 43 & 33 \\
Color/smell of vaginal discharge since birth & 76 & 41 & 34 \\
Condition of perineum & 96 & 58 & 43 \\
Fever & 38 & 37 & 22 \\
\hline
\end{tabular}

At the one week consultation, providers were less likely to inquire about these danger signs, with a mean composite score of 1.59 out of four. By six weeks, less than a third of providers asked about any of the key danger signs. Bleeding and infection are two of the main complications in the postpartum period and are relevant up to six weeks. Some women may experience infected perineum and may not volunteer information to the provider unless specifically asked. This area of postpartum care requires further improvement. Given the life-threatening nature of hemorrhage and sepsis, screening for danger signs as part of postpartum care requires further improvement as the mean composite score at six weeks was only 1.08 out of 4. 
Counseling on danger signs: Most providers do give messages to the mother on possible danger signs at 48 hours; excessive bleeding (76\%), foul smelling vaginal discharge (59\%) and broken episiotomy scar $(83 \%)$. In a third of consultations at one and six weeks providers were observed giving this information to women.

Physical examination conducted: The following elements were reviewed: observe general appearance, take temperature, pulse, BP, check for pallor, examine breasts and nipples, palpate abdomen for uterine involution. Table 7 outlines the components carried out by time period, although measurement of temperature and pulse are less likely to be done over time. The total mean scores (out of 7) were: at 6.65 at 48 hours, 5.25 at one week, and at 5.45 at six weeks.

Table 7: Proportions of measurements and examinations done for the mother during the three postpartum consultations after the intervention

\begin{tabular}{l|ccc}
\hline Indicator & $\begin{array}{c}\mathbf{4 8} \text { hours } \\
(\mathbf{n = 3 4}) \\
\%\end{array}$ & $\begin{array}{c}\mathbf{1} \text { week } \\
(\mathbf{n = 5 1 )} \\
\%\end{array}$ & $\begin{array}{c}\mathbf{6} \text { weeks } \\
(\boldsymbol{n}=\mathbf{5 0}) \\
\%\end{array}$ \\
\hline Observe general appearance & 100 & 94 & 92 \\
Take temperature & 91 & 45 & 57 \\
Take pulse & 84 & 27 & 37 \\
Take blood pressure & 100 & 90 & 90 \\
Check eyelids and palms for pallor (anemia) & 100 & 92 & 88 \\
Examine breasts and nipples & 100 & 90 & 90 \\
Palpate abdomen for uterine involution & 100 & 86 & 92 \\
\hline
\end{tabular}

Tests conducted: After the intervention, HIV tests were carried out at the one week postpartum consultation in seven percent of the consultations in the hospital $\mathrm{MCH}$ clinic $(\mathrm{n}=36)$ and in 20 percent of the consultations at the health centers $(n=15)$. But no counseling and testing for HIV was observed being carried out during any of the six-week consultations, which may be attributable to the high proportion (89\%) of women testing during ANC consultations and so are likely to already know their status.

Counseling for STI/HIV: (actions observed: discuss STI symptoms/signs, effects of HIV/STI in postpartum period, inquire presence of STI/HIV, discuss STI/HIV risk factors, inquire about STI/HIV risk factors, discuss prevention of STI/HIV, condom use, and partner CT for HIV). STI and HIV risk factors were discussed in 58 percent of the consultations on the postnatal ward. Other areas discussed include; how to prevent STI/HIV and the use of condoms (52\%); and partner counseling and testing (39\%). Many women during the one week and six week consultations were not counseled in STI/HIV.

In summary, Table 8 shows that overall quality of care is poor. The highest score was recorded within the maternity unit of the hospital. In some areas providers are performing well but there are still areas of improvement required. 
Table 8: Summary of quality of care indices for maternal health during first 6 weeks

\begin{tabular}{l|ccc}
\hline \multirow{2}{*}{ Composite indicators } & $\begin{array}{c}\mathbf{4 8} \text { hours } \\
(\boldsymbol{n}=\mathbf{3 4})\end{array}$ & $\begin{array}{c}\mathbf{1} \text { week } \\
(\boldsymbol{n}=\mathbf{5 1})\end{array}$ & $\begin{array}{c}\mathbf{6} \text { weeks } \\
(\boldsymbol{n}=\mathbf{5 0})\end{array}$ \\
\cline { 2 - 4 } Asking about danger signs since childbirth $(0-4)$ & 2.65 & 1.59 & 1.08 \\
Physical examination conducted $(0-7)$ & 6.65 & 5.25 & 5.45 \\
Record of tests conducted $(0-2)$ & 0.20 & 0.10 & 0.00 \\
Family planning $(0-4)$ & 2.44 & 1.24 & 1.88 \\
Counseling on HIV/STIs $(0-8)$ & 2.42 & 1.52 & 1.04 \\
Total index for maternal health $(\mathbf{0}-\mathbf{2 5})$ & $\mathbf{1 5 . 3 6}$ & $\mathbf{8 . 4 6}$ & $\mathbf{9 . 4 5}$ \\
\hline
\end{tabular}

\section{Essential newborn care}

Asking about danger signs since birth: During the 48-hour consultations, providers were observed asking mothers if their newborns had difficulty breathing (21\%) or feeding (29\%), such as poor sucking or not sucking and if the baby felt too hot or too cold (15\%). The mean composite score was 0.65 out of 3 . At the one week consultation, around just over a third of the providers asked about the three dangers signs, with an overall composite score of 1.10 out 3 .

Counseling on danger signs specific to the early postpartum period: The key danger signs are difficulty breathing, difficulty feeding, and baby has fever/ too cold. During the consultations within 48 hours, the danger signs mothers were most frequently counseled on were: redness around umbilical stump and feeding difficulties (32\%), temperature control and breathing difficulties (26\%). The mean composite score for quality of counseling at 48 hours was 0.85 out of $3(28 \%)$. Temperature control (30\%), feeding difficulties (45\%) redness around umbilicus (32\%) and breathing difficulty (34\%) were the most frequently mentioned danger signs by providers in the one week consultations. Comparisons between the pre- and post-intervention groups at the six week consultation did not show any improvements. This may be due to the fact that student nurses were carrying out some of the consultations. Nevertheless the overall quality of care provided remained weak.

Immunizations received: Relevant immunizations (Polio, BCG, DPT) were given in the majority of observed interactions. The proportion of infants observed receiving both BCG and polio on the ward was high, at $97 \%$. During the one week consultation, the newborns that received Polio (46\%) and BCG (42\%) were mainly those who were born at home or in a health centre. The others had already received theirs while in the hospital. This demonstrates that the one week consultation provides an opportunity to immunize those infants not immunized at birth. During almost all the consultations at six weeks infants received DPT and Polio (94\%).

Infant feeding counseling: (advice on infant feeding, encourage mother to discuss management of breastfeeding and re-emphasis of exclusive breastfeeding). Table 9 indicates that health providers appear to be more competent in counseling on infant feeding than the other elements of maternal and infant health care. 
Table 9: Infant feeding counseling at 48 hours, one week and 6 week consultations postintervention

\begin{tabular}{l|ccc}
\hline Indicator: & 48 hours & 1 week & $\mathbf{6}$ weeks \\
\hline & $(\mathbf{n = 3 4 )}$ & $\mathbf{( n = 5 1 )}$ & $\mathbf{( n = 5 0 )}$ \\
Advice on infant feeding & $\%$ & $\%$ & $\%$ \\
Encourage mother to discuss management & 97 & 92 & 84 \\
Re-emphasize exclusive breastfeeding & 81 & 74 & 66 \\
\hline
\end{tabular}

At six weeks, hospital staff performed significantly better than health centre staff (97\% vs. 61\%). There was also a significant increase in providers requesting mothers to demonstrate breastfeeding at the six week consultation ( $29 \%$ vs. $66 \%$ ), as well as in the assessment of how the baby suckled ( $26 \%$ vs. $68 \%)$.

Table 10 describes the overall scores for the quality of newborn and infant health care provided at the three consultations, indicating that they fall short of what is desirable. This indicates that essential newborn care is a neglected area and needs to be addressed in the implementation of actions for accelerating reduction of maternal and newborn morbidity and mortality.

Table 10: Summary of mean scores of quality of care indices for infant health during the first 3 postpartum assessments

\begin{tabular}{l|ccc}
\hline \multirow{2}{*}{ Indices } & $\mathbf{4 8}$ hours & $\mathbf{1}$ week & $\mathbf{6}$ weeks \\
\cline { 2 - 4 } & $\mathbf{( n = 3 4 )}$ & $\mathbf{( n = 3 8 )}$ & $\mathbf{( n = 5 0 )}$ \\
Asking about any danger signs $(0-3)$ & 0.65 & 1.10 & 0.68 \\
Counseling on possible danger signs $(0-3)$ & 0.85 & 1.08 & 0.68 \\
Counseling on infant feeding $(0-3)$ & 2.44 & 2.35 & 2.14 \\
Immunizations received $(0-2)$ & 1.9 & 0.90 & 1.90 \\
Total quality of care index for newborn $(\mathbf{0}-\mathbf{1 1})^{\star \star}$ & $\mathbf{5 . 8 4}$ & $\mathbf{5 . 4 3}$ & $\mathbf{5 . 4 0}$ \\
\hline
\end{tabular}

\section{Quality of care at the six-week visit}

Comparisons of the quality of care for maternal and infant health provided at six weeks were possible between the pre- and post-intervention groups (see Table 11). Overall, the total scores for the quality of care provided reduced significantly over time. The only significant improvements were observed in the overall physical examination of the mother and counseling on infant feeding. While these improvements are encouraging, the constant redeployment of staff is having an obvious negative effect on the overall quality of care in the long term. 
Table 11: Summary of quality of care indices for maternal and infant health at six weeks

\begin{tabular}{|c|c|c|}
\hline \multirow{2}{*}{ Composite indicators } & $\begin{array}{c}\text { Pre-intervention } \\
(n=38)\end{array}$ & $\begin{array}{c}\text { Post-intervention } \\
(n=50)\end{array}$ \\
\hline & Average score & Average score \\
\hline Asking about danger signs since childbirth $(0-4)^{\star *}$ & 2.29 & 1.08 \\
\hline Physical examination conducted $(0-7)^{*}$ & 5.08 & 5.45 \\
\hline Family planning $(0-4)^{\star \star}$ & 2.87 & 1.88 \\
\hline Counseling on HIV/STIs* $(0-8)$ & 5.13 & 1.04 \\
\hline Total score for maternal health $(0-23)^{\star \star}$ & 15.37 & 9.45 \\
\hline Asking about any danger signs $(0-3)^{\star \star}$ & 1.58 & 0.68 \\
\hline Counseling on possible danger signs $(0-3)^{\star *}$ & 1.79 & 0.68 \\
\hline Counseling on infant feeding $(0-3)^{* *}$ & 1.97 & 2.14 \\
\hline Immunizations received $(0-2)^{\star *}$ & 1.97 & 1.90 \\
\hline Total quality of care index for newborn $(0-11)^{\star \star}$ & 7.31 & 5.40 \\
\hline
\end{tabular}

$* \mathrm{p}<0.05 * * \mathrm{p}<0.01$

\section{Counseling on return to fertility and family planning}

Table 12 describes the quality of counseling on fertility and family planning observed after the intervention on the ward and in the PNC clinic. Among those women counseled on FP, two or more methods were discussed in 76 percent of the 48 hour consultations and in 41 percent of the two week and 62 percent of the six week consultations. At the six week consultation, 67 percent of clients received their preferred method. The mean composite scores for the quality of FP counseling after the intervention were highest during the 48 hour consultations, with a mean score of 2.44 out of a possible four items discussed, whereas at the one week consultation the mean score was 1.24 out of four and 1.88 at six weeks.

Table 12: Proportion of women receiving counseling on FP and fertility post-intervention

\begin{tabular}{l|ccc}
\hline \multicolumn{1}{c|}{ Indicators } & \multicolumn{3}{c}{ Consultations } \\
\hline & $\mathbf{4 8}$ hours & $\mathbf{1}$ week & $\mathbf{6}$ weeks \\
\cline { 2 - 4 } & $(\mathbf{n = 3 3 )}$ & $(\mathbf{n = 5 1 )}$ & $(\mathbf{n = 5 0})$ \\
& $\%$ & $\%$ & $\%$ \\
Return to fertility & 33 & 31 & 52 \\
Return to sexual activity & 71 & 20 & 56 \\
Advising on FP & 82 & 47 & 56 \\
Healthy timing and spacing of pregnancies & 61 & 35 & 50 \\
\hline
\end{tabular}


None of the women received a FP method on the postnatal ward, even though the majority of women were observed being given FP information (82\%). The potential of women to adopt a long-acting method was constrained by the fact that no clinically-skilled FP provider was available during 2007.

At the one-week consultation, 27 percent of women were using an FP method. At the 6 week consultation post intervention, in 68 percent of consultations a client took a method home. Providers at the hospital were much more likely to counsel women on FP methods compared to those in the health centers ( $58 \%$ vs. $20 \%$ ). In addition, postpartum women were more likely to receive their preferred method in hospitals than in health centers (33\% vs. $7 \%)$. More women were observed receiving the method they said they preferred to have during the 6 week consultation than at one week (48\% vs. $8 \%)$.

Table 13 describes the FP methods that postpartum women were observed deciding to use during the one week and six week consultations. The data were collected concurrently using the same observation checklist in the four health facilities and observing the same providers. It appears that at the one week visit women are less likely to be thinking of FP methods and more likely to be concerned with their newborn. After the intervention, the lower level of FP use during the six week visits (68\% vs. 95\%) may be because there were stock outs of some of the FP methods, and a staffing crisis in the $\mathrm{MCH}$ hospital. Alternatively more postpartum women may have started using FP as a result of the one week visit. There were no doctors or clinical nurses available in the hospital to insert IUD at the endline and nursing assistants are not qualified to insert IUDs. However, among those using FP methods there were slight increases following the intervention. The proportions do not add up to $100 \%$ because of some dual method use by those using condoms.

Table 13: FP methods chosen or started by women during consultations at one week and 6 weeks

\begin{tabular}{|c|c|c|c|}
\hline \multirow[b]{2}{*}{ Indicator } & \multirow{2}{*}{$\begin{array}{c}1 \text { week } \\
\begin{array}{c}\text { Post-intervention } \\
(\mathrm{n}=51)\end{array}\end{array}$} & \multicolumn{2}{|c|}{6 weeks } \\
\hline & & $\begin{array}{l}\text { Pre-intervention } \\
\qquad(\mathrm{n}=38)\end{array}$ & $\begin{array}{l}\text { Post-intervention } \\
\qquad(n=50)\end{array}$ \\
\hline Any FP method chosen during consultation & $27 \%$ & $95 \%$ & $68 \%$ ** \\
\hline Among those using FP & $\begin{array}{c}(n=14) \\
\%\end{array}$ & $\begin{array}{c}(n=60) \\
\%\end{array}$ & $\begin{array}{c}(n=34) \\
\%\end{array}$ \\
\hline Progestin only pill & 50 & 14 & 24 \\
\hline Injectable & 29 & 30 & 30 \\
\hline Condoms & 29 & 25 & 29 \\
\hline IUD † & 0 & 31 & 0 ** \\
\hline LAM only & 0 & 0 & 3 \\
\hline Natural FP (SDM) & 0 & 0 & 3 \\
\hline
\end{tabular}

${ }^{* *} \mathrm{p}<0.01$ between pre and post intervention at 6 weeks only

$\dagger$ No doctor available in hospital to insert IUD at endline 


\section{Rapport with clients}

An index score was calculated for observations after the intervention of client-provider rapport at 48 hours, one week and six weeks using nine indicators (provider greeted the client, ensured confidentiality, ensured privacy, asked the client how she was feeling, looked at client's health card during consultation, asked if there were any concerns, asked if client understood all information, courteous to client throughout, give client a return date). Out of a maximum score of nine, the mean score was 8.1 during the 48 hour consultation, 7.5 at one week and 7.8 at six weeks, indicating very high levels of rapport established by the providers with their clients. Table 14 describes the individual components. There was a non-significant drop in the level of rapport after the intervention (8.05 vs. 7.8).

Table 14: Degree of rapport observed between clients and providers

\begin{tabular}{l|ccc}
\hline \multicolumn{1}{c|}{ Indicators } & $\begin{array}{c}\mathbf{4 8} \text { hours } \\
(\boldsymbol{n = 3 4 )} \\
\text { \% }\end{array}$ & $\begin{array}{c}\mathbf{1} \text { week } \\
(\boldsymbol{n = 5 1 )} \\
\%\end{array}$ & $\begin{array}{c}\mathbf{6} \text { weeks } \\
(\boldsymbol{n = 5 0 )} \\
\%\end{array}$ \\
\hline Greet the patient & 100 & 100 & 98 \\
Ensure privacy & 100 & 96 & 94 \\
Ensure confidentiality & 91 & 51 & 60 \\
Ask the client how she is feeling & 94 & 63 & 92 \\
Look at the client's health card during examination & 97 & 96 & 92 \\
Ask if there are any concerns/encourage questions & 82 & 80 & 76 \\
Ask if the client has understood all information & 67 & 80 & 82 \\
Give return date & 97 & 98 & 94 \\
Courteous to the client throughout & 94 & 98 & 90 \\
\hline
\end{tabular}

\section{Acceptability of new postpartum services}

\section{Provider satisfaction}

The majority $(70 \%)$ of health care providers interviewed after the intervention thought it is a good idea to offer extra consultations to women in the immediate postpartum period. The main reasons given included: observing if the child is growing well, checking the mother's health, providing more health education, monitoring for signs of complications in mother and baby, and reinforcing counseling.

However some service providers believed that even though most providers and clients appreciated the new one week postpartum consultation, there was room for improvement. The main challenges include lack of equipment, inappropriate infrastructure (e.g. rooms too small, insufficient privacy and confidentiality, weak communication systems, lack of staff or overworked staff, lack of key skills and knowledge).

"I would like to indicate some of the benefits of this one week PNC program which is in relation to those women who deliver at home. When they have tears we are able to repair them before they heal on their own or before they get infected." Provider Informant BB 
Good client-provider relationships or rapport remained high. Providers in health centers were significantly more likely than those in hospitals to encourage postpartum women to ask questions ( $89 \%$ vs. $68 \%$ ) and ask if the client understood everything, which may be due to the greater work load in the hospital.

\section{Integration of services during the postpartum period}

All health care providers, both in the government and CHAL institutions, indicated during the FGDs being generally satisfied with how they integrate the services (PNC, PMTCT and FP) during the postpartum period. The few exceptions were in busy clinics with limited providers where it became a challenge to provide all the relevant services at the same time. One informant admitted "...however, these days it seems like we focus more on these issues (HIV and PMTCT) and forget about others services like postnatal care and family planning..." In providing improved postpartum services, a number of health providers indicated that they were keen to implement a home visiting strategy to follow up new postpartum women in their own homes so that nurses would be able to assess clients in an appropriate atmosphere where the client is relaxed.

"We are short staffed and the work becomes so heavy at times. We are just three at this facility, me, a registered nurse and a trained nursing assistant, and we are not on duty all at the same time. When we are all on duty which is rare, we manage very well. It would be good if we could have more staff." Provider Informant BB District

\section{Client satisfaction}

All women at both baseline and endline said they thought it important for the mother to return after delivery for a checkup. The most commonly cited reasons were: to check the mother's health, check the uterus has contracted, check cesarean section or perineal scars, check for any complications, for follow up of CD4 count, information on HIV and AIDS, check and prevent transmission of HIV to baby and family planning.

Not surprisingly all postpartum women expect to bring their infant back for a check-up. The main reasons were growth monitoring, immunizations, check any abnormalities danger signs and feeding. There was general consensus among women in the FGDs that the one week check was a good idea. Some providers thought that women might not come at one week because of problems and cost of transport, but this was not raised by the women.

"The one week post natal program is an appropriate one and I wish it could be rolled out to the entire country because it assists us in discovering problems early and then we can give the appropriate management of such problems before complications arise." Provider Informant BB Hospital

At the endline, women were more likely to say that a check-up within one week was important, with an increase from 27 percent to 35 percent, and were more likely to think that the next visit should be at six weeks (from $50 \%$ to $78 \%$ ). Significantly more women think the mother should be checked at least 3 times, increasing from 4 to 44 percent $(p<0.01)$ and that the infant should be checked at least three times, from 11 to 73 percent $(\mathrm{p}<0.01)$. 
There was an overwhelming increase in the proportion of women who were asked to come back for a postpartum check, from 54 percent to 82 percent. Eighteen percent were asked to come back after one week and a further 74 percent were asked to come back at 6 weeks. More women were given an exact date to return at endline (89\%) than at baseline $(54 \%)$.

"When I came here, my child was weighed and examined. I was also examined, my breasts and lochia. I was also asked if the baby is still breast feeding well. I think it (one week assessment) is good and should continue." Client BB district

Respect and friendliness were the first requirements for the provision of quality health care services expressed by women during FGDs. Although the majority of women interviewed on the ward were reasonably happy with the care they received, some of the informants in the FGDs thought that a few of the nurses and doctors in the public institutions did not always treat them with respect, were insensitive and appeared to not really care about clients; for example, some women had been sent away because they had arrived after $10 \mathrm{am}$. In addition, limited space and privacy was available in one institution where women are expected to stand holding their babies before being attended.

Some respondents recommended that there should be an increase in the number of trained staff working in the facilities to reduce waiting time and to provide more time for consultations. They would like women who attended the services at one week to be seen before the others because 'they were still weak'. Clients attending both CHAL and Government institutions had similar opinions regarding integration of services. During the FGDs, they indicated that they were given health education sessions on topics like HIV and AIDS, ARVs and how to take care for themselves and their infants after delivery.

Service statistics from the district public health nurse show large increases in the number of women attending the hospital MCH clinic for postpartum care, from 261 in 2006 to 612 in 2007; data from health centers were not available. Table 15 shows detail from the newly introduced postnatal register, recording number of postpartum women and their infants seeking care in the hospital and three health centres. Some women who delivered at home attended within 48 hours.

Table 15: Number of women attending postpartum care following introduction of postnatal registers in MCH-FP

\begin{tabular}{|c|c|c|c|c|c|c|}
\hline Indicator & \multicolumn{2}{|c|}{ March } & \multicolumn{2}{|c|}{ April } & \multicolumn{2}{|c|}{ May } \\
\hline All assessments carried out in $\mathrm{MCH}$ : & Hosp & HCs & Hosp & HCs & Hosp & HCs \\
\hline Postnatal assessment 1 (48 hours)* & 0 & 4 & 5 & 13 & 6 & 8 \\
\hline Postnatal assessment 2 (1 week) & 13 & 31 & 24 & 32 & 28 & 12 \\
\hline Postnatal assessment 3 (6 weeks) & 40 & 63 & 30 & 42 & 29 & 38 \\
\hline
\end{tabular}

* This does not include the women who delivered on postnatal ward.

Data from the registers collated from the hospital between March and May $2007(\mathrm{n}=132)$ demonstrated that 81 percent of women seen at the six week consultation received a FP method of their choice. Among HIV-positive postpartum women, 78 percent received a method compared to 83 percent HIV-negative postpartum women. 


\section{Women's knowledge and experiences during labor and postpartum period}

Knowledge of maternal danger signs: When interviewed at 48 hours after delivery, more women could recall at least two danger signs in the mother after than before the intervention (63\% vs. $57 \%$ ). However, women's knowledge was mixed. While there was an increase in knowledge of excessive bleeding as a complication (from 48\% to 60\%), there was a decrease in knowledge of foul vaginal discharge (from $24 \%$ to $13 \%$ ) and broken episiotomy scar or tear (from $43 \%$ to $33 \%$ ).

Knowledge of danger signs in the newborn: After the intervention, there was a non-significant increase in the proportion of women at 48 hours after delivery who could state at least two danger signs $(63 \%$ vs. $70 \%)$. Knowledge that feeding difficulties was a danger sign increased $(61 \%$ vs. $70 \%$ ) and about high or low body temperature increased (48\% vs. 52\%), although knowledge on newborn breathing difficulties and inflamed umbilicus remained low (25\% vs. $22 \%)$.

Immunizations: At endline all women said that their infants had received Polio and BCG immunizations on the postnatal ward, compared to 80 percent and 9 percent respectively at baseline.

Infant feeding practices: Fewer women interviewed at 48 hours on the postnatal ward reported breastfeeding at endline than at baseline (75\% vs. $83 \%)$. Replacement feeding also dropped (6\% vs. $11 \%)$. However more postpartum women said they were mixed feeding (7\% vs. $19 \%)$ at endline. This is surprising as all women were interviewed within 48 hours of giving birth on the postnatal ward.

Table 16 shows that of those women who were breastfeeding on the ward, more were able to breastfeed their newborn within one hour of delivery at endline. Significantly more women were able feed within 15 minutes ( $20 \%$ vs. $42 \%$ ). However around three quarters women had to move to the postnatal ward before feeding their newborn.

Table 16: Postpartum women recall how soon to breastfed baby after delivery

\begin{tabular}{l|cc}
\hline Indicator & $\begin{array}{c}\text { Pre- } \\
\text { intervention } \\
(\mathbf{n}=\mathbf{4 6})\end{array}$ & $\begin{array}{c}\text { Post- } \\
\text { intervention } \\
(\mathbf{n}=\mathbf{6 4 )}\end{array}$ \\
How soon after birth breastfeed: & $\%$ & $\%$ \\
Within one hour * $^{*}$ & 80 & 87 \\
One to two hours** & 11 & 0 \\
Two or more hours & 9 & 6 \\
Replacement feeding & 11 & 6 \\
\hline
\end{tabular}




\section{Follow up counseling and support in the postpartum period}

HIV tests: Table 17 indicates that majority of postpartum women interviewed had been tested for HIV during ANC, probably due to the National PMTCT program and support from the USAIDfunded Partnership for Family Centered HIV Programs. Women and their partners are increasingly likely to share results but with no significant changes between the two surveys.

Table 17: Client HIV testing behavior

\begin{tabular}{l|cc}
\hline Indicator & $\begin{array}{c}\text { Pre- } \\
\text { intervention } \\
(\mathrm{n}=46) \\
\%\end{array}$ & $\begin{array}{c}\text { Post- } \\
\text { intervention } \\
(\mathrm{n}=64)\end{array}$ \\
Ever had HIV test ** & 80 & $\%$ \\
Of those tested: & $(\mathbf{n = 3 7 )}$ & 98 \\
Tested at VCT site & 5 & $\mathbf{( n = 6 3 )}$ \\
Tested at ANC site & 92 & 3 \\
Tested in the labor ward & 0 & 92 \\
Tested in postnatal ward & 3 & 2 \\
Client shared results & 57 & 3 \\
Partner tested & 16 & 82 \\
Partner shared results & 83 & 30 \\
\hline
\end{tabular}

Use of HIV care and support services by HIV+ postpartum women and their infants: When asked if they knew their HIV status, few women (9\% and $11 \%)$ did not know their status; these women had been tested but not yet received their results. Of those that did know their status, none refused to disclose their status to the interviewer. The same proportion (16\%) of women reported being HIV positive at baseline and endline. This proportion is supported by national services statistics that show 20 percent of pregnant women who were tested during ANC services at Butha Buthe Hospital in 2007 were recorded as HIV positive (MOHSW 2008).

The proportion of HIV-positive postpartum women who said they took Nevirapine during labor increased from 7 out 12 at baseline to 7 out of 9 at the endline. Likewise, the proportion of infants receiving Nevirapine after birth increased from 7 out of 12 to 7 out of 9 . At endline, all seven infants received Nevirapine immediately after birth, demonstrating a strong commitment to PMTCT by nursing staff in the maternity unit. There was a slight increase among HIV-positive postpartum women who were referred to the ART clinic, from two out of 12 to five out of nine, and six women wanted more information on where to go for support. None of the HIV-positive postpartum women knew to start their infant on cotrimoxazole prophylaxis at six weeks at baseline, but eight of nine said they would do so at the endline. 


\section{Fertility and family planning intentions}

\section{Postpartum women's FP experience and fertility intentions}

Overall, there was a decrease after the intervention in the proportion of women who recalled that the provider discussed FP methods during the ANC consultations (48\% vs. 37\%). Discussion of the female condom increased significantly from 22 percent to 50 percent, but vasectomy and emergency contraception were not mentioned at all, in either baseline or endline. Discussion around the advantages of LAM increased slightly from 2 percent to 12 percent, but remained low.

\section{Figure 2: Proportion of women who 'wanted' their most recent pregnancy}

$* \mathrm{p}<0.05$

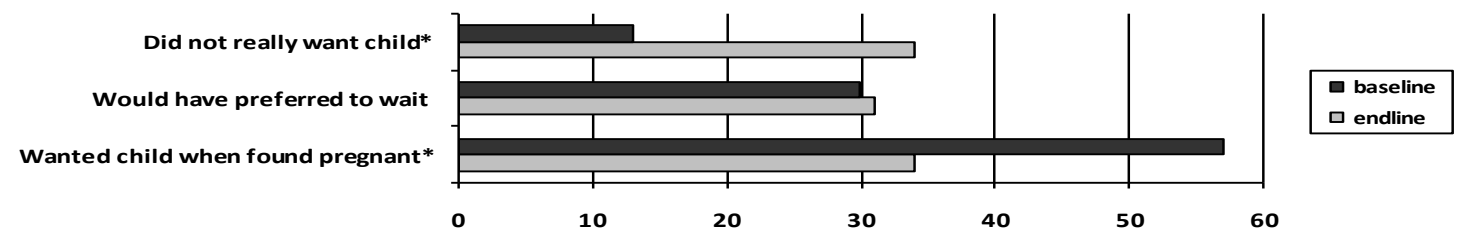

There was clearly an unmet need for family planning among this group of postpartum women. Women on the postnatal ward were asked whether they had wanted to be pregnant when they found out they were carrying the recently delivered infant. Figure 2 demonstrates a significant decrease among those who said they wanted to be pregnant then and significant increases among those who did not really want to be pregnant at all. As might be expected, women with low parity tended to want more children. However age is not significantly related to "wantedness" of the previous pregnancy.

Women remained uncertain as to how soon a woman can get pregnant again after giving birth; there was no change between baseline and endline of the proportion who knew the correct answer, at around 30 percent. Those women who said they did not know reduced from 49 to 41 percent, but those that gave an incorrect answer increased from 20 to 29 percent.

Women were asked how soon they intended to return to sexual activity after giving birth. The proportion intending to wait six months or more decreased from 69 percent at baseline to 48 percent at endline. Significantly fewer women wanted to wait more than one year (39\% vs. 19\%), but significantly more women did not know when they might become sexually active again (9\% vs. $26 \%$ ).

One-third of women at endline did not intend to have any more children and one-quarter intended to wait more than two years. The older the woman, the less likely she was to want more children. More women said they did not know or it was not their decision on when to have another child. Women did not necessarily agree with their husband on the desired number of children, with a notable reduction in agreement at endline (Table 18). 
Table 18: Postpartum women intentions for further children

\begin{tabular}{l|cc}
\hline Indicator & $\begin{array}{c}\text { Baseline } \\
(\mathbf{n = 4 6 )} \\
\%\end{array}$ & $\begin{array}{c}\text { Endline } \\
(\mathbf{n = 6 4 )} \\
\mathbf{\%}\end{array}$ \\
\hline Do not intend to have any more children & 30 & 34 \\
Intention to have more children & $\mathbf{n = 3 3}$ & $\mathbf{n = 4 2}$ \\
Intention to have another child in two to three years & 9 & 17 \\
Intention to have another child after three years** & 78 & 24 \\
Does not know / not my decision** & 13 & 59 \\
Husband wants same number of children* & 52 & 33 \\
Husband wants more children & 20 & 36 \\
Husband wants fewer children & 17 & 6 \\
Don't know how many children husband wants & 11 & 22 \\
\hline
\end{tabular}

Due to the small number of HIV positive women who were interviewed, the analysis did not yield any significant findings about HIV status and intention to have more children. However, five out of six HIV-positive women at baseline and nine out of ten HIV-positive women at endline said they did not intend to have more children. Some informants in the FGDs said that knowing their HIV status had influenced their decision about having further children. Similar proportions of HIV-positive women intended to start using FP, pre and post intervention, by six weeks (three out of six vs. four out of ten); and by six months (five out of six vs. eight out of ten).

\section{Family planning information}

Women on the postnatal ward were asked their preferred timing for a provider to discuss family planning with them. Just over half of both the pre-intervention (53\%) and post-intervention (56\%) groups preferred to receive FP information during pregnancy. More post intervention women expressed a preference for FP information at the 6 week consultations (30\% vs. 9\%). Few are interested in information at the time of delivery, or on the postnatal ward. Different women have different needs and therefore FP information should be offered at every opportunity. After the intervention, significantly fewer women ( $48 \%$ vs. $37 \%)$ recalled being given any information during ANC on child spacing, although more women at endline said they were given information on child limiting $(46 \%)$. Likewise, significantly fewer women reported discussing any FP methods on the postnatal ward ( $61 \%$ vs. $41 \%$ ), although the majority of providers were observed counseling women on FP.

\section{Women's intentions and use of FP postpartum}

The proportion of women on the postnatal ward who had ever used FP increased slightly after the intervention from 48 percent to 58 percent. Women who said they intended to use an FP method within six weeks of birth reduced significantly after the intervention from 80 to 52 percent. More women post intervention said they intended to start FP between 6 weeks and 6 months (33\% vs. $0.4 \%$ ). This could be attributable to the emphasis placed on encouraging LAM or on other HIV messages in Lesotho promoting abstinence among people living with HIV/AIDS. 
Although the mean age of women pre and post intervention was different, age was not significantly related to intention to use FP methods at either 6 weeks or six months. Nevertheless $83 \%$ of both groups intended to use an FP method by six months (table 19).

Table 19: Intended use of FP methods at six weeks and six months

\begin{tabular}{|c|c|c|c|c|}
\hline \multirow[b]{2}{*}{ Indicator } & \multicolumn{2}{|c|}{$\begin{array}{l}\text { six weeks } \\
\text { after delivery }\end{array}$} & \multicolumn{2}{|c|}{$\begin{array}{l}\text { six months } \\
\text { after delivery }\end{array}$} \\
\hline & $\begin{array}{c}\text { Pre- } \\
\text { intervention } \\
(n=46)\end{array}$ & $\begin{array}{c}\text { Post- } \\
\text { intervention } \\
(n=64)\end{array}$ & $\begin{array}{c}\text { Pre- } \\
\text { intervention } \\
(n=46)\end{array}$ & $\begin{array}{c}\text { Pre- } \\
\text { intervention } \\
(n=64)\end{array}$ \\
\hline Client intends to use an FP method & $80 \%$ & $52 \%$ & $83 \%$ & $84 \%$ \\
\hline $\begin{array}{l}\text { Of those intending to use FP at six } \\
\text { weeks after delivery: }\end{array}$ & $\begin{array}{l}\text { Pre- } \\
(n=37)\end{array}$ & $\begin{array}{l}\text { Post } \\
(n=33)\end{array}$ & $\begin{array}{l}\text { Pre- } \\
(n=38)\end{array}$ & $\begin{array}{l}\text { Post } \\
(n=54)\end{array}$ \\
\hline Injectables & 78 & 58 & 71 & 63 \\
\hline Progestin only pill & 14 & 27 & 13 & 17 \\
\hline Condom (male or female) & 16 & 18 & 11 & 15 \\
\hline Sterilization male & 00 & 6 & 13 & 6 \\
\hline IUD** & 30 & 3 & 21 & 4 \\
\hline Hormonal implants & 0 & 3 & 3 & 4 \\
\hline Sterilization female & 0 & 3 & 0 & 2 \\
\hline Combined oral pill & 11 & 0 & 0 & 2 \\
\hline Emergency contraception & 0 & 0 & 0 & 2 \\
\hline LAM & 0 & 0 & 0 & 2 \\
\hline
\end{tabular}

Table 19 shows that the most popular methods clients intend to use within 6 weeks and six months of giving birth were injectables and progestin only pills (POP). There was significant reduction in intention to use the IUD, but this may be attributable to stock outs and lack of skilled staff and therefore the method may not be encouraged. However there were small but discreet increases in intended uptake of other long-acting methods such as female sterilization and hormonal implants.

One fifth of women thought that they would use LAM as their initial method of contraception. At endline, 89 percent of those using LAM could recall the three components compared to eight percent at baseline. There was a reduction in the proportion of women given condoms to take home, from 28 percent at the baseline to 13 percent at the endline.

Some of the main reasons why women did not intend to take up family planning include the following: husband away (i.e., many Basutho men are migrant workers in South Africa), family do not believe in using FP, fear of side effects, limited information and lack of access. This is particularly pertinent if the nearest health facility is supported by the Roman Catholic Church and therefore FP methods are not available. It is possible that the FP information given to the women on the postnatal ward by the providers may have been the first time they had received information and were therefore confused. 
If a woman attended a CHAL clinic for ANC then it is very unlikely she would have received any FP information. In addition, there was limited knowledge about the different methods, as well as some misperceptions. For example: "Women may feel dizzy", "fall pregnant anyway" or "husbands complain that they do not enjoy sex when women use contraceptives".

\section{DISCUSSION}

This study set out to develop and introduce a strengthened postpartum care package with three topic-specific consultations - within 48 hours, within two weeks, and at six weeks - and to determine the acceptability and quality of the improved postpartum care. The postpartum care package in Lesotho expanded the content of existing services to incorporate essential maternal and newborn care in the first potentially risky days after childbirth but at the same time provide opportunities to inform and provide appropriate family planning advice and methods within the context of a high HIV environment.

Health provider capability for the range of services required for targeted postpartum care remains weak in some aspects. Although some providers were knowledgeable about different elements of maternal and newborn complications, the overall levels of knowledge remained at less than half the maximum score. Gaps in provider knowledge of appropriate FP methods for the different postpartum periods were also noted. Although all providers interviewed interacted with women for postpartum services in the facilities, a number had not been formally trained in the provision of all family planning methods. In addition, many student nurses are seconded to the hospital for their clinical experience and due to staff shortages are sometimes expected to work with limited supervision. Nursing assistants do not always have the capacity to provide all the required aspects of care, including provision of long-acting methods of FP.

There is also a gap in policy. There is no formal FP training in the country, resulting in widespread lack of skills, which has led to only short-acting FP methods being made available. More resources will need to be directed towards training providers to enable them to provide comprehensive postpartum care, including family planning. Due to the rapid turnover of staff and deployment practices, few nurses remain in the same health centre or unit for more than six months, which means that constant training is required. Policy on deployment of staff also needs reviewing.

Strengthening postpartum care and postpartum family planning was expected to result in significantly better quality of care. The introduction of the intervention had a positive effect on some aspects of quality of care in terms of the maternal physical examination and infant feeding counseling. Despite some scores doing well against the standard norms the total scores were only a third of the expected results and quality of care significantly decreased. The study assessed the capacity of each MCH unit as a whole, rather than individual providers. These results however reflect the situation on the ground where constant rotation of staff in $\mathrm{MCH}$ departments in the hospital and the health centres reduces the impact of any training intervention. The weaker aspects of comprehensive PNC will need increased attention as the package is rolled-out nationally. 
Health providers seemed to be both satisfied and confident with the care they give postpartum women. The complaints recorded were mainly system and infrastructure related and not inherent to the approach itself. For example the high workload and inadequate training could be resolved by deploying well-trained staff with the appropriate skills. Any shortages experienced in relevant equipment, commodities and supplies cuts across all RH services. However data from the health facility assessment indicated that each facility was sufficiently prepared prior to the intervention to provide postpartum care.

Women demonstrated their acceptability of the services by attending the additional postpartum services and liking the services as demonstrated from participants' comments in the FGDs. The introduction of the new postnatal register has resulted in recording each of the new postpartum visits to the $\mathrm{MCH}$ and the increase in women attending the one week visit. All providers expressed enthusiasm for the new postnatal register piloted during the intervention. The Family Health Department of the MOHSW reviewed the register with national stakeholders and the updated version of the postnatal register has been printed and distributed throughout the country.

In conclusion, providers and postpartum women in Butha Buthe district were supportive of the timings of the new postpartum package of services. The MOHSW must now make efforts to sustain this initiative and roll out to the rest of the country. Early visits are crucial to prevent maternal and newborn morbidity and mortality as well as counseling for family planning method. The results of this study have come at an opportune time and will feed into new initiatives currently underway. Feedback from national stakeholders following the dissemination meeting in March 2008 included overwhelming support for scaling up the number, timing and content of postpartum consultations that a woman and her newborn should receive and especially the assessment within 48 hours and the one week postpartum visit. The development of the orientation package and the technical aids, as well as the new postnatal register, provides building blocks for the MOHSW to take the opportunity to strengthen integrated postpartum care across the country. Integrating MNH and HIV and AIDS-PMTCT and FP services within a comprehensive postpartum package can ensure adequate quality of care.

\section{RECOMMENDATIONS}

The following recommendations emerged from discussions with stakeholders:

- Strengthen policies related to the continuum of care for maternal, newborn and infant health and linked to HIV/PMTCT/ strategies.

- Facilitate the necessary system processes through organizational changes, such as allocation of staff, availability of physical space and equipment/ supplies and efficient client flow, as they are critical for the adequate provision of the new focused postpartum services.

- Finalize and scale up Focused Postpartum Care. All training materials and job aids developed by MOHSW and PC may be formally adopted for scaling up PNC.

- Strengthen PNC linkages between the facility and community levels and institutionalize the new package. 
- Develop a family planning training strategy especially to update providers' skills for providing long-acting methods.

- In CHAL institutions, which are Roman Catholic, encourage LAM and fertility-based awareness methods.

- Suggest roles for $\mathrm{CHWs}$ on MNH/FP activities including the provision of counseling during home visits and community mobilization activities on preventive aspects of care, identification of danger signs, ANC and PNC periods for the mother and baby. 


\section{REFERENCES}

Adair, Tim. 2007. "Desire for Children and Unmet Need for Contraception Among HIV Positive Women in Lesotho," DHS Working Papers, Demographic and Health Research.

Calverton, Maryland, USA: Macro International.

Butchart, W.A., B.L. Tancred, and N. Wildman. 1999. "Listening to women: focus group discussions of what women want from postnatal care," Curationis 22(4): 3-8. South Africa: Department of Nursing, University of Cape Town.

Fort, Alfredo L., Monica T Kothari, and Noureddine Abderrahim. 2006. "Postnatal care: Levels and determinants in Developing Countries." Calverton, Maryland, USA: Macro International.

Gray, Glenda and James McIntyre. 2007. "HIV and Pregnancy," British Medical Journal 334, pp. 950-953. doi:10.1136/bmj.39176.674977.

Health Planning and Statistics Department. 2008. "Ministry of Health and Social Welfare Annual Joint Report, 2007/2008."

Horizons Program and University of Cape Town Faculty of Health Sciences. 2005. "Exploring Current Practices in Paediatric Antiretroviral Rollout and Integration with Early Childhood Programmes in South Africa: A Rapid Situational Analysis," Horizons Research Update. Washington, DC: Population Council

MEASURE DHS ORC. 2005. "Lesotho Demographic and Health Survey 2004." Calverton, Maryland, USA: Macro International.

McIntyre, James. "Maternal Health and HIV," Reproductive Health Matters 13(25): 129-135.

Moodley, J. 2003. “Saving Mothers: 1999-2001,” South African Medical Journal 93(5): 364-366. Pretoria, South Africa: National Committee on Confidential Enquiries into Maternal Deaths.

Ministry of Health, 2005. "Joint Review of the National HIV/AIDS Response." Lesotho.

Kerber, K., J. de Graft- Johnson, Z.A. Bhutta, P. Okong, A. Starrs, and J. E. Lawn. 2007. "Continuum of care for maternal, newborn and child health from slogan to service delivery," The Lancet 370(9595): 1358-1369.

Lewis, Gwyneth. 2004. "Beyond the numbers: reviewing maternal deaths and complications to make pregnancy safer." Geneva: Department of Reproductive Health and Research, World Health Organization.

Lugina, Helen I., Gunilla Lindmark, Eva Johansson, and Kyllike Christensson. 2001. "Tanzanian midwives' views on becoming a good resource and support person for postnatal women," Midwifery 17(4): 267-278. 
Myer, L., M. Rabkin, E. Abrams, A. Rosenfield, and W. El-Sadr. 2005. "Focus on Postnatal women: Linking HIV Care and Treatment with Reproductive Health Services in the MTCT-Plus Initiative," Reproductive Health Matters 13(25).

Phafoli, S. 2007. "Report on acceptability of PNC in Lesotho.” (unpublished). Population Council.

Rutenberg, Naomi and Carolyn Baek. 2004. "Review of field experiences: Integration of family planning and PMTCT services.” Washington, DC: Population Council.

Rutenberg, Naomi, Carolyn Baek, Sam Kalibala, and James Rosen. 2003. "Evaluation of a United Nations-supported pilot projects for the prevention of mother-to-child transmission of HIV.” New York: UNICEF and Population Council.

Sines, E., U. Syed, S. Wall, and H. Worley. 2007. "Postnatal Care: Critical Opportunity to Save Mothers and Newborns," Policy Perspectives on Newborn Health. Washington, DC: Population Reference Bureau and Save the Children.

Stephenson, P. 2008. "Global Discussion: Health Timing and Spacing of Pregnancy." ppfp@ibp.wa-research.ch

Strachan M., A. Kwateng-Addo, K. Hardee, S. Subramaniam, N. Judice, and K. Agarwal. 2004. "An analysis of family planning content in HIV/AIDS, VCT and PMTCT policies in 16 countries," Policy Working Papers Series no. 9. Washington, D.C: POLICY.

Tuoane, 2004. Personal communication.

UNICEF. 2005. "Report on Evaluation of Emergency Obstetric Care in Lesotho."

Warren, C., P. Daly, L. Toure, and P. Mongi. 2006. "Postnatal care," in J. Lawn and K. Kerber (eds.), Opportunities for Africa's Newborns. Cape Town, South Africa: Partnership for Maternal, Newborn and Child Health, pp. 79-90.

WHO. 2005. "World Health Report Make Every Mother and Child Count." Geneva: World Health Organization. 


\section{Appendix 1a: Job aids for health care providers}

Contraceptive methods appropriate in the extended postpartum period for breastfeeding women $^{4}$

\begin{tabular}{|c|c|c|}
\hline $\begin{array}{l}\text { First choice: } \\
\text { Methods do not interfere with } \\
\text { breastfeeding and are safe to } \\
\text { use any time after birth }\end{array}$ & $\begin{array}{l}\text { Second choice: } \\
\text { Methods contain hormone } \\
\text { progestin and do not affect a } \\
\text { woman's milk supply. } \\
\text { Recommended from six weeks } \\
\text { after delivery }\end{array}$ & $\begin{array}{l}\text { Third choice: } \\
\text { Methods reduce a } \\
\text { woman's milk supply. } \\
\text { Delay the use of such } \\
\text { methods until } 6 \\
\text { months postpartum. }\end{array}$ \\
\hline $\begin{array}{l}\text { LAM } \\
\text { Condoms } \\
\text { IUD } \\
\text { Vasectomy } \\
\text { Tubal Ligation }\end{array}$ & $\begin{array}{l}\text { Progestin only pill } \\
\text { Progestin-only injectables (depo } \\
\text { provera) } \\
\text { Implants }\end{array}$ & $\begin{array}{l}\text { Combined oral } \\
\text { contraceptive } \\
\text { Combined injectable }\end{array}$ \\
\hline
\end{tabular}

\section{1b: Job aid adapted from WHO $2006^{5}$}

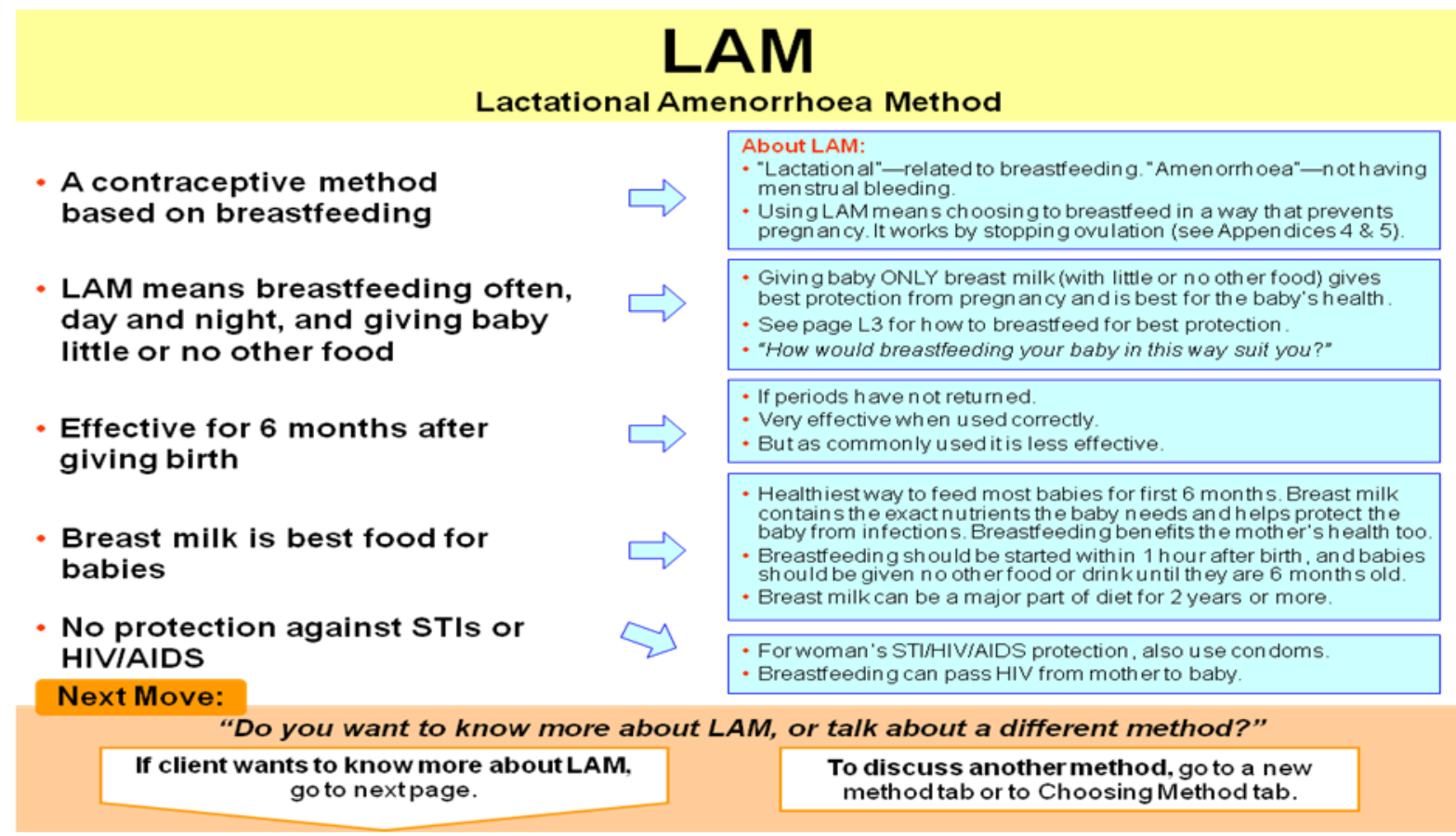

$4 \quad$ Global Health Technical Brief Family Planning for Postpartum women: seizing a missed opportunity by Patricia Stephenson and Patricia MacDonald USAID 2005

5 Reproductive Health Needs for People Living with HIV and AIDS 


\section{1c: Postpartum check list for mothers and newborns}

\section{Checklist for postpartum \& newborn assessment on the postnatal ward before the mother and infant are discharged home $\&$ first week consultation in clinic}

\begin{tabular}{|c|c|}
\hline Mother & Baby \\
\hline How is the lochia loss? & What is the baby's body temperature? \\
\hline Is the perineum intact, episiotomy or tear repaired? & Is the cord bleeding or oozing pus? \\
\hline Is mother counseled on personal hygiene \& nutrition & Was eye ointment applied? \\
\hline $\begin{array}{l}\text { Does mother know the correct position and attachment } \\
\text { for breastfeeding }\end{array}$ & $\begin{array}{l}\text { What is the weight of the baby? } \\
\text { Is the baby feeding well? }\end{array}$ \\
\hline $\begin{array}{l}\text { Is mother on a birth spacing method? Think LAM where } \\
\text { appropriate? }\end{array}$ & $\begin{array}{l}\text { Has baby received Nevirapine? (where } \\
\text { applicable) }\end{array}$ \\
\hline Did the mother receive vitamin A? & Has the baby received birth Polio and BCG? \\
\hline $\begin{array}{l}\text { Are vital signs for TPR and BP taken? } \\
\text { Have you provided \& counseled any prescribed drugs? }\end{array}$ & $\begin{array}{l}\text { Have you provided and counseled on } \\
\text { prescribed drugs? }\end{array}$ \\
\hline $\begin{array}{l}\text { Does the mother know the danger signs during the } \\
\text { puerperium? }\end{array}$ & $\begin{array}{l}\text { Does the mother know the danger signs of the } \\
\text { newborn? }\end{array}$ \\
\hline Are findings recorded in the postpartum register? & Are findings recorded in the postnatal register? \\
\hline When is the next assessment? (give date) & When is the next assessment? \\
\hline
\end{tabular}


Appendix 2: Parent baby leaflet

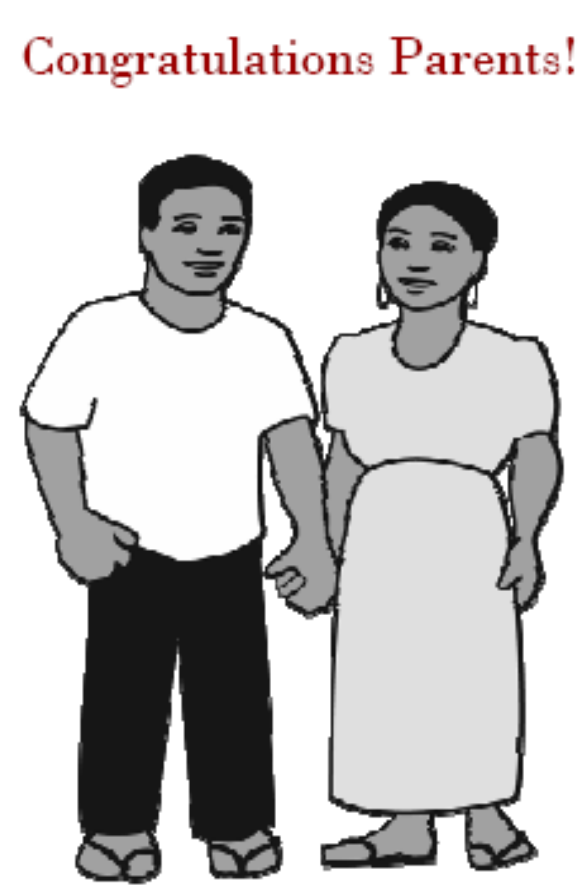

You are giving the greatest and most wonderful gift of all: LIFE!

\section{Give your newborn baby}

a good start in life

Here you will find information on essential care of yourself and also for your baby, from the moment of birth, through the first few months

\section{FOR THE MOTHER:}

It is important for you to keep healthy after the birth of your baby. You should go for a check up the same time as your baby at one week, six weeks and six months.

Fathers should provide emotional and physical support to their partners during the first few weeks. A new mother should not be left alone for at least the first 3 to 7 days.

To speed up healing following the birth and to prevent infection, mothers should take daily baths and change pads frequently.

Mothers should eat nutritious foods and drink plenty of fluids.

Healthy timing and spacing of pregnancies have positive effects for both mother and baby. Discuss with the health care provider about the best family planning method to suit you, during the next few weeks /months.

If you are exclusively breastfeeding, your baby is less than 6 months and you have not started your menses yet, this is called LAM and this will protect you against pregnancy (but all three must be there for it to work)

\section{Danger signs in the mother}

If a mother has any of the following, she must seek care from the health facility:

- Swelling of face, hands feet

- Fever

- Foul smelling vaginal discharge

- Lower abdominal pain

- Heavy bleeding or clots

- Pus or bleeding from $\mathrm{C} / \mathrm{S}$ site

- Engorged breasts, cracked nipples

Promote healthy behaviours

Be prepared for complications - be aware of the danger signs and seek care early.

Know your HIV status and know where to access further information and health services that you and your baby might require.

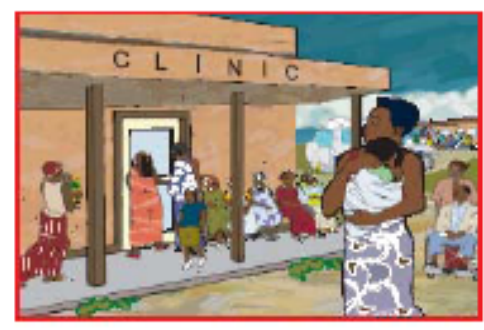

Look after yourself well for the sake of 


\section{FOR YOUR BABY:}

\section{Dry and warm}

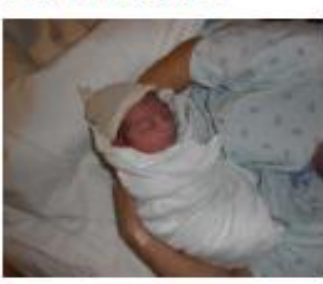

Keep the baby's head and body dry and warm from the moment of birth. It doesn't matter if the weather is hot. The baby should not be bathed until at least 24 hours afterbirth.

Bathe the baby from the second day on; dry your baby properly and keep it warm.

\section{Breastfeeding}

The baby should

start breastfeeding within the first half hour after birth. ust give your baby your milk, and no other food or liquid, until your baby is 6 months old

Mother's milk helps the baby to grow up healthy and also protects it against infections.

For more effective breastfeeding:

Wash your hands before feeding your baby.

Give your baby your breast milk on demand, at least 10 times during day and night. When your baby is sick, breastfeed more often. Wash your nipples once a day with a sponge or wet cloth and warm water.
If you get sick or upset, keep feeding the baby. Diseases and moods are not carried through the milk.

Umbilical and eye care

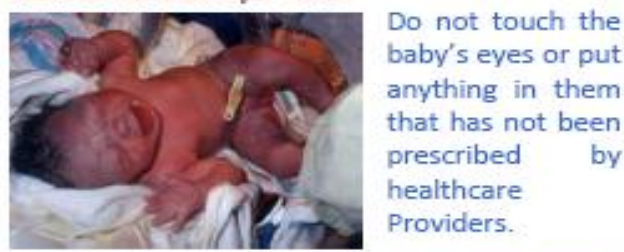

Let the umbilical cord dry and fall off on its own.

Do not put anything Do not put anything on it. Take your baby to centre for his or her first check-up within 3 to 7 days after it is born, whether the baby is sick or not and again at 6 weeks.

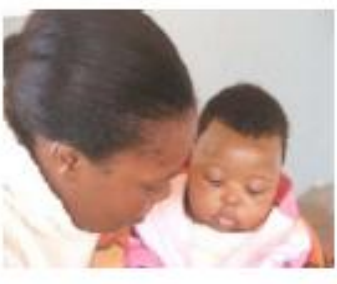

\section{Immunisations}

In addition to the BCG and polio your baby should receive within a few days of birth, your baby will need further immunisations at 6 weeks, 10 weeks, 14 weeks (polio, DPT and Hepatitis B) and again at 9 months (measles).

At 18 months your baby should receive immunisations for measles and DT.

Bring your baby to the clinic to be weighed monthly so that we can check that your baby is growing well.
Depending on your HIV status you will receive additional care for your baby.

\section{Danger signs in the newborn}

a) Poor or no breastfeeding

b) Too cold or too hot to touch

c) Lethargy/floppy

d) Convulsions

e) Abdominal distention/vomiting

f) Difficulty breathing

g) Swelling, redness, pus around umbilicus.

If any of the above occur take your baby to the hospital immediately.

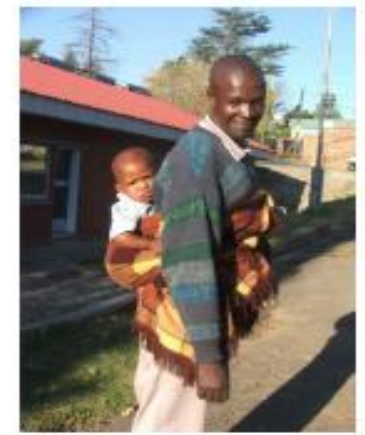

Fathere can help too when the baby is small and while he is growing up: 